\title{
Measurement and Characterization of Space Shuttle Solid Rocket Motor Plume Acoustics
}

\author{
Jeremy Kenny \\ NASA Marshall Space Flight Center \\ Huntsville, AL \\ Chris Hobbs \& Ken Plotkin \\ Wyle Laboratories \\ Arlington, VA \\ Debbie Pilkey \\ ATK Space Systems \\ Promontory, UT
}

Lift-off acoustic environments generated by the future Ares I launch vehicle are assessed by the NASA Marshall Space Flight Center (MSFC) acoustics team using several prediction tools. This acoustic environment is directly caused by the Ares I First Stage booster, powered by the five-segment Reusable Solid Rocket Motor (RSRMV). The RSRMV is a larger-thrust derivative design from the currently used Space Shuttle solid rocket motor, the Reusable Solid Rocket Motor (RSRM). Lift-off acoustics is an integral part of the composite launch vibration environment affecting the Ares launch vehicle and must be assessed to help generate hardware qualification levels and ensure structural integrity of the vehicle during launch and lift-off.

Available prediction tools that use free field noise source spectrums as a starting point for generation of lift-off acoustic environments are described in the monograph NASA SP-8072: "Acoustic Loads Generated by the Propulsion System." This monograph uses a reference database for free field noise source spectrums which consist of subscale rocket motor firings, oriented in horizontal static configurations. The phrase "subscale" is appropriate, since the thrust levels of rockets in the reference database are orders of magnitude lower than the current design thrust for the Ares launch family. Thus, extrapolation is needed to extend the various reference curves to match Ares-scale acoustic levels. This extrapolation process yields a subsequent amount of uncertainty added upon the acoustic environment predictions. As the Ares launch vehicle design schedule progresses, it is important to take every opportunity to lower prediction uncertainty and subsequently increase prediction accuracy. Never before in NASA's history has plume acoustics been measured for large scale solid rocket motors.

Approximately twice a year, the RSRM prime vendor, ATK Launch Systems, static fires an assembled RSRM motor in a horizontal configuration at their test facility in Utah. The remaining RSRM static firings will take place on elevated terrain, with the nozzle exit plume being mostly undeflected and the landscape allowing placement of microphones within direct line of sight to the exhaust plume. These measurements will help assess the current extrapolation process by direct comparison between subscale and full scale solid rocket motor data. The RSRM plume free field noise spectrums can also be used directly to update the NASA SP-8072 database and eliminate the need to 
extrapolate full scale motor behavior. This enhancement of the prediction state of the art will be used in support of the whole Ares launch family.

Acoustic free-field data collected during three RSRM static tests are reviewed. These tests are designated Technical Evaluation Motor (TEM) - 13, Flight Verification Motor (FVM) - 2, and Flight Support Motor (FSM) - 15. The acoustic team consists of ATK Launch Systems, Wyle, and Marshall Space Flight Center acoustic engineers. ATK engineers placed microphones on the RSRM outer case and out in the field. The Wyle and Marshall Space Flight Center team placed microphones along the exhaust plume in a near-field linear array, and in circular far-field arrays.

In addition to the free field data, acoustic measurements were taken on the four segment reusable solid rocket motor. The microphones are located along the motor case at 180 degrees (on "top" of the motor). As shown in figure 1, the measurements for this study are located on the forward segment, the aft center segment, and the aft dome of the motor. Measurements have been collected for several tests, many of those in conjunction with the free field array. The data is collected at 100,000 samples per second using a WIN600 data recorder. The microphones are rocket noise type manufactured by Endevco. Overall sound pressure levels on the motor vary with distance from the nozzle exit plane, and can be higher than 140 decibels near the exit plane, to just over 130 decibels at the forward segment of the motor, as seen in figure 2. While the horizontal configuration for static test is not entirely representative of launch pad, where the vehicle will be in the vertical position, it still provides valuable information. Model correlation can be achieved with the data, and dynamic and acoustic environments can be developed and verified. Little recent acoustic information is available to NASA for this type of verification activity.
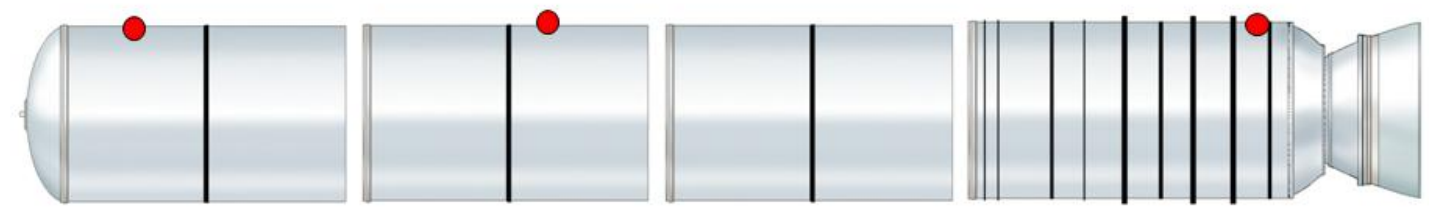

Motor Microphones

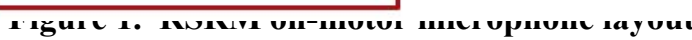




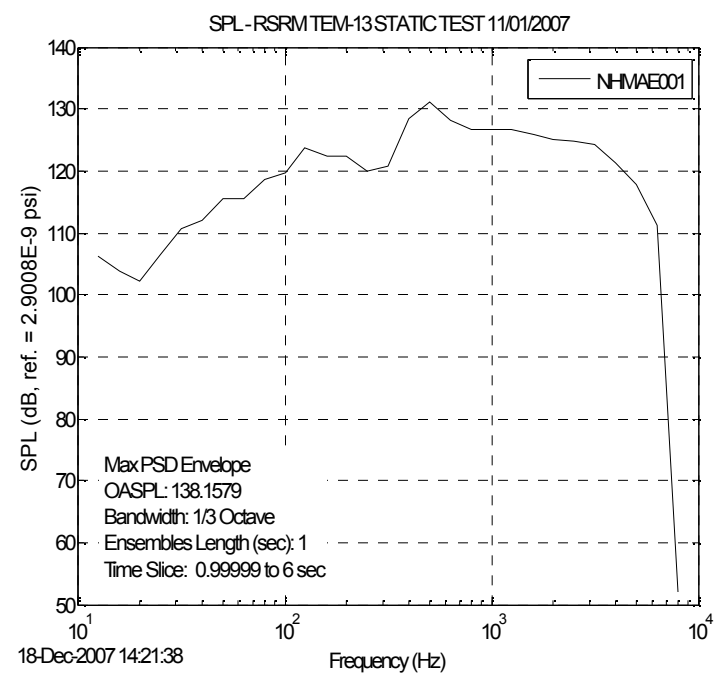

Figure 2. Sound pressure levels for microphone on aft dome, TEM-13 static test

For the first two static tests, two types of acoustic arrays were used in the free field. A linear array was used to collect near-field acoustics used for beamforming efforts to identify noise sources within the plume. A circular array was used in the farfield to assess plume directivity and overall sound power levels. Figure 3 shows the microphone layout used for the TEM-13 test. 1/3 octave band sound pressure levels for the various microphone measurements are shown in figures 4 and 5.

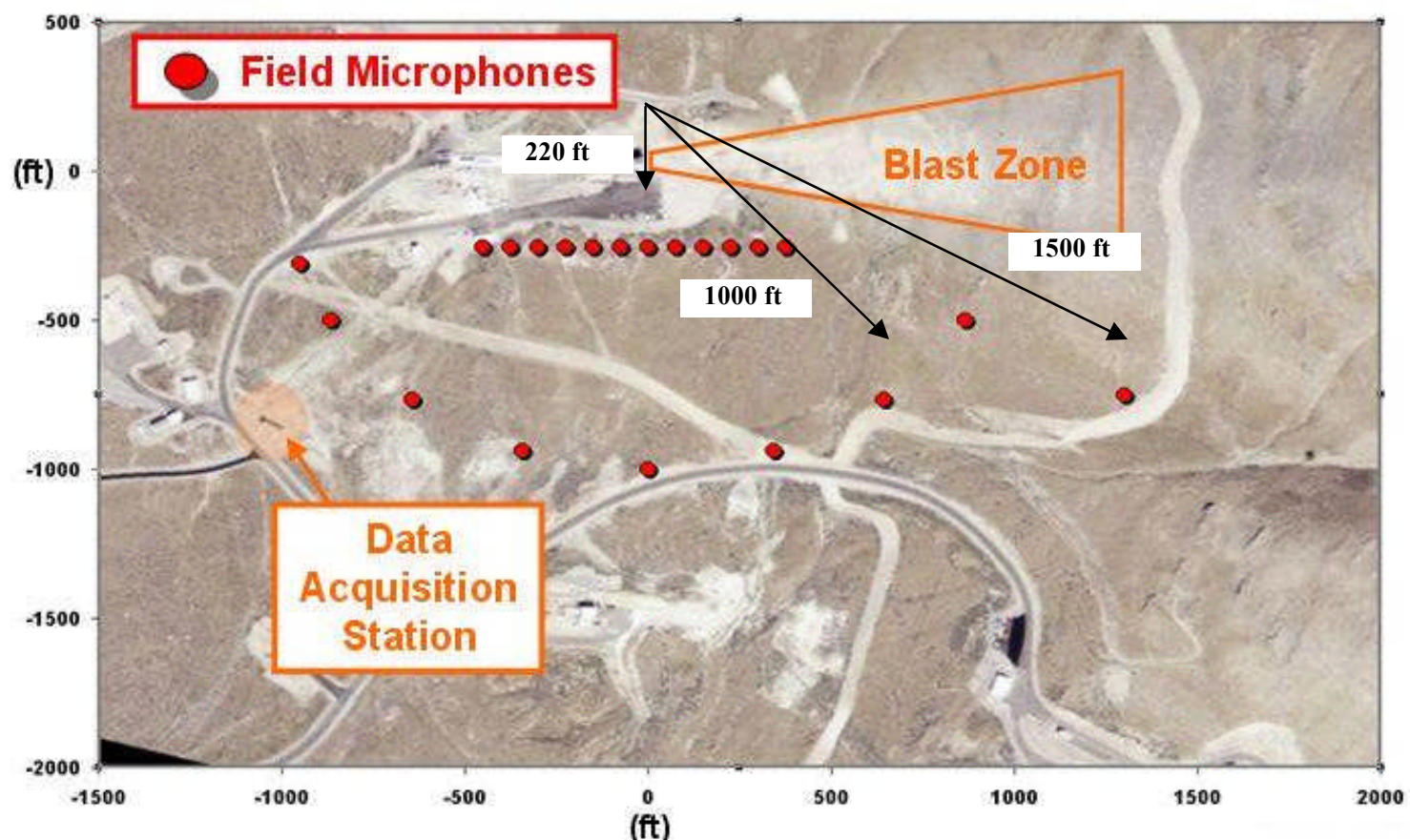


Figure 3. TEM-13 microphone layout

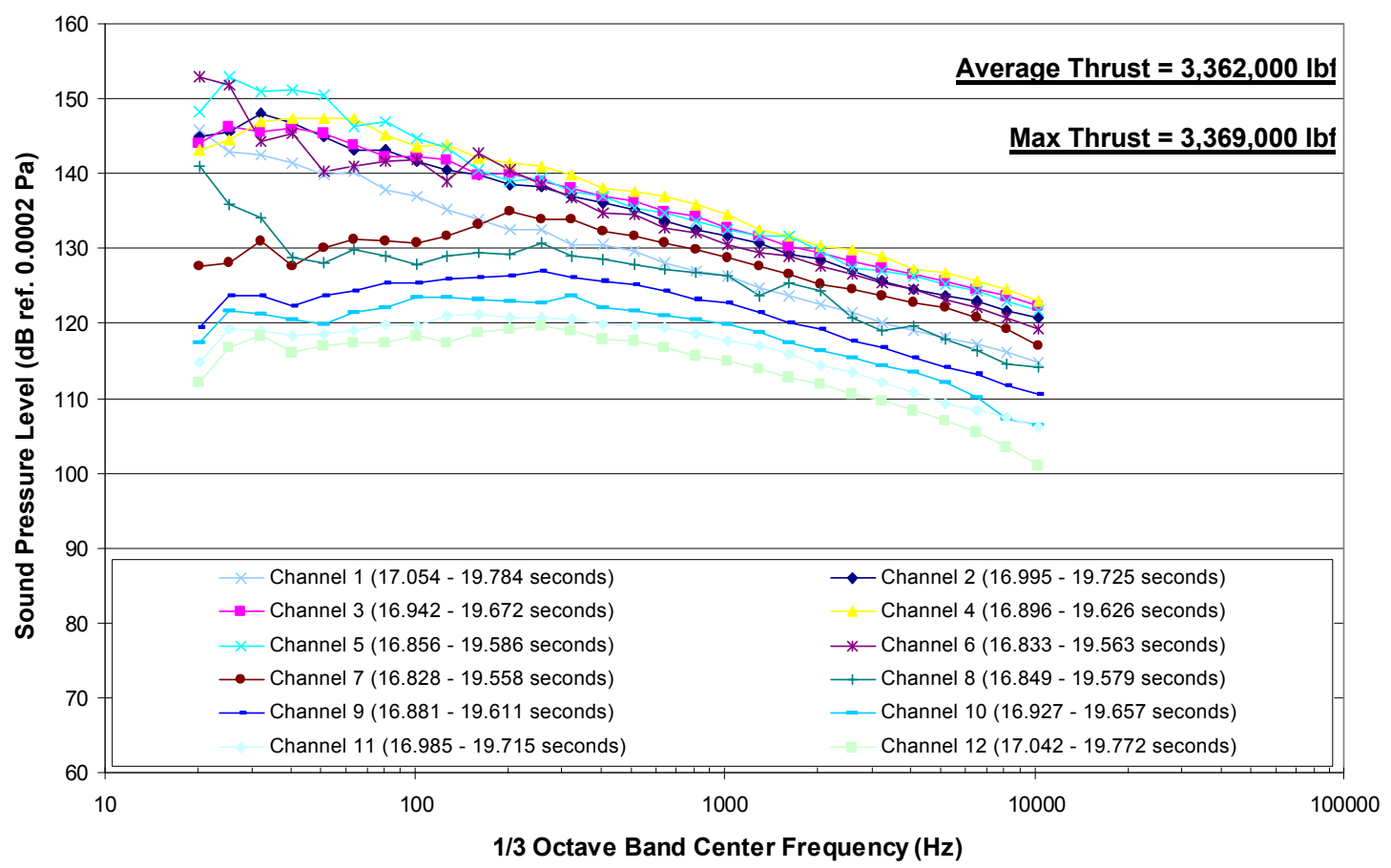

Figure 4. Sound pressure levels for microphone near field locations for the TEM-13 static test

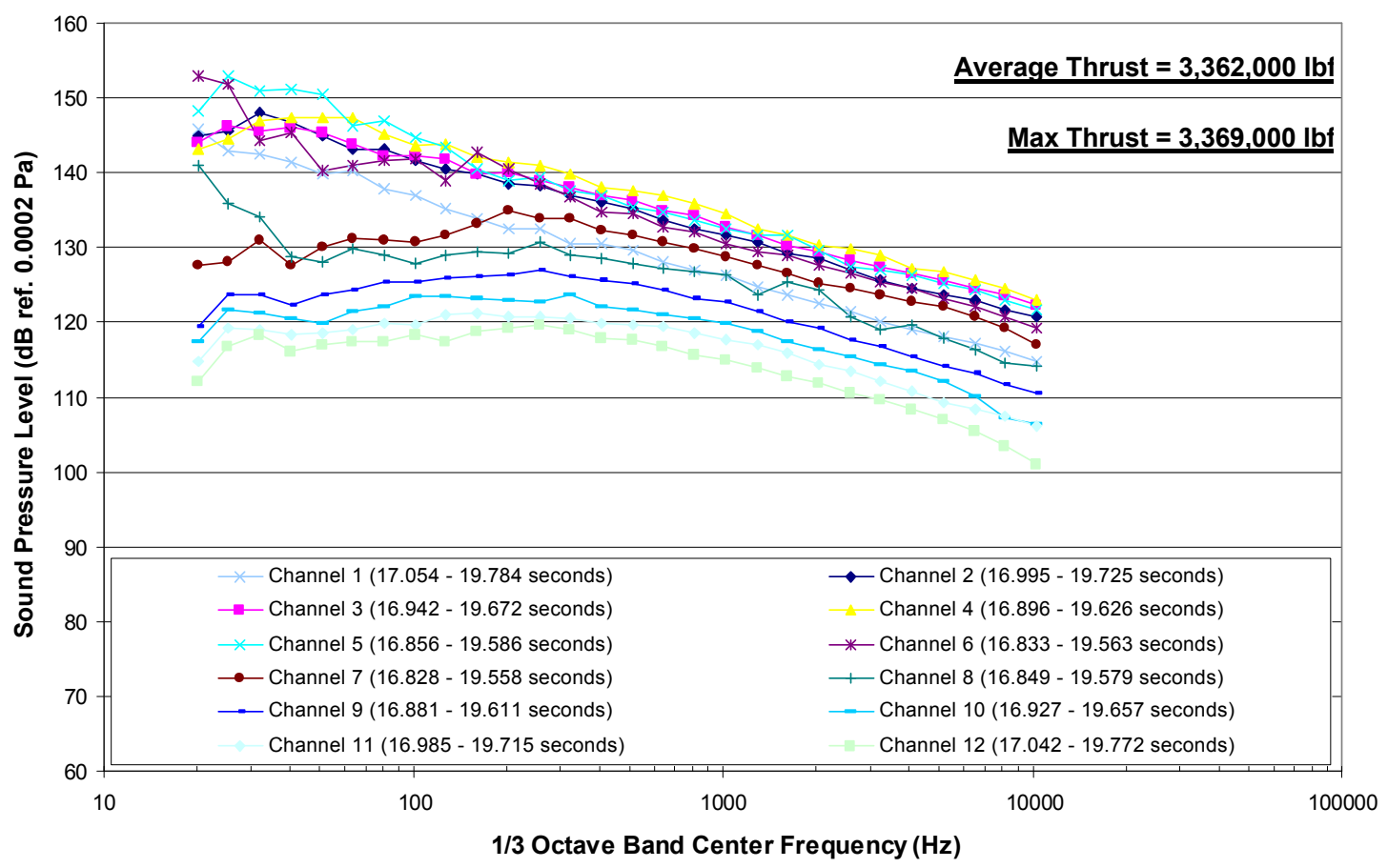

Figure 5. Sound pressure levels for microphone far field locations for the TEM-13 static test 
The second static test had approximately the same far field array as the first test, and the near field array was oriented to ascertain for jet noise source locations via beamforming techniques. Test results showed similar sound pressure levels to the first test, with effects of ground reflections clearly seen in the data. Directivity curve comparisons with NASA SP-8072 and the measured data show reasonable agreement for higher angles, but some departure between prediction and measurement for shallower angles closer to the nozzle centerline.

For the third static test (FSM-15), the microphones will be more concentrated near the nozzle exit plane and the blast zone. Additional microphones will be placed in the far field to pick up information deemed missing from the first two attempts at collecting the acoustic data. Beamforming techniques will also be employed on the measurements for noise source identification.

This paper will investigate implications to classically used methodology from NASA SP-8072 due to the newly acquired data from full-scale RSRM motor firings. The data collection efforts will be explained, including the rationale for microphone location placement, hardware selection, and terrain challenges. Data analysis and test to test correlation, terrain correction, and validation activities are explained in detail. Finally, a comparison of RSRM motor acoustics and other smaller scale motors from NASA SP8072 will be made. 


\title{
Measurement and Characterization of Space Shuttle Solid Rocket Motor Plume Acoustics
}

\author{
R. Jeremy Kenny ${ }^{1}$ \\ NASA-Marshall Space Flight Center, Huntsville, AL, 35812 \\ Chris Hobbs ${ }^{2}$ and Ken Plotkin ${ }^{3}$ \\ Wyle Laboratories, Arlington, VA, 22202 \\ and \\ Debbie Pilkey ${ }^{4}$ \\ ATK Space Systems, Promontory, UT, 84302
}

Acoustic free-field data collected during three reusable solid rocket motor (RSRM) static tests are reviewed. The acoustic team consists of ATK Space Systems, Wyle Laboratories, and MSFC acoustic engineers. ATK engineers placed microphones on the RSRM outer case and out in the field. The Wyle and Marshall Space Flight Center (MSFC) team placed microphones along the exhaust plume in a near-field linear array and in circular far-field arrays. The character of the acquired data and the scope of its usefulness will be examined here.

\section{Introduction}

$\mathrm{N}$ ASA's Constellation program is currently developing two new launch vehicles These vehicles, known as the Ares I and Ares V, will transport astronaut crew and cargo to the International Space Station and the Moon. Both launch vehicle designs will employ solid rocket motor boosters during the lift-off and ascent phases of a given mission. Specifically, the Ares I design will use a five-segment solid rocket booster powered by the five-segment reusable solid rocket motor (RSRMV). The RSRMV design is based in part on the space shuttle reusable solid rocket motor (RSRM) design. The Ares V lift-off propulsion system will also use a five-segment solid rocket motor design in conjunction with a group of liquid rocket engines. ${ }^{1}$

Large payload launch vehicles (e.g., Ariane V, space shuttle) require lift-off propulsion systems with high thrust and plume exit velocity values. The product of thrust and exit velocity gives a representation of the flow stream power being generated by the lift-off propulsion system. Through various thermo-fluidic mechanisms, a portion of this flow stream power is converted to acoustic power radiated from the plume as pressure waves. These acoustic pressure waves will travel radially outward from the plume, including along the launch vehicle itself. Launch vehicle structures can be excited dynamically by the induced acoustic environment, raising structural vibration levels. If the induced vibration levels are too high, the structures must be re-designed until the structure qualification levels are satisfied. Failure of the structure to meet these qualifications levels can threaten vehicle structural integrity and hardware operability during lift-off.

Integral to the Ares I and Ares V launch vehicle design process is the assessment of induced vibration levels upon the launch vehicle structures during lift-off. The Ares I and Ares V lift-off acoustic environments are predicted by the NASA Marshall Space Flight Center (MSFC) acoustics team. The predicted acoustic environments are then

\footnotetext{
${ }^{1}$ Engineer, Acoustics and Stability Team, M//S ER42, NASA-MSFC, AL, 35812, Member, AIAA.

${ }^{2}$ Senior Acoustician, 241 18th Street, Suite 701, Arlington, VA, 22202, Member, AIAA.

${ }^{3}$ Chief Scientist, 241 18th Street, Suite 701, Arlington, VA, 22202, Senior Member, AIAA.

${ }^{4}$ Loads \& Environments Specialist, UT40-LF3, P.O. Box 707, Brigham City UT, 84302-0707, Member, AIAA.
} 
delivered to launch vehicle structural analysts who create hardware qualification levels by which the launch vehicle components and structures are designed. This design process is cyclical. New acoustic environment predictions, based on changes in state-of-the-art understanding, are continually released that can update structural designs and qualification levels. One user of the Ares I predicted acoustic environment is the Ares I first stage booster program office. Structural components located on and within the first stage booster need to be qualified against the composite induced vibration environment during lift-off, which includes the RSRMV plume-generated acoustics. Lift-off acoustic environment prediction tools must then be enhanced, whenever the opportunities arise, to give the best accuracy and to prevent erroneous predictions of first stage structural qualification levels.

Several lift-off acoustic environment prediction tools that are employed at MSFC are those found in the monograph NASA SP-8072 "Acoustic Loads Generated by the Propulsion System". ${ }^{2}$ This monograph uses a reference database for free-field noise source spectrums, which consist of measured acoustics from horizontallytested subscale rocket motor firings. The subscale free-field noise source spectrums are scaled to frequency and amplitude levels representative of the RSRMV geometry and flow stream power. The scaled spectrums are corrected for vertical flight configuration effects, including launch pad reflections and acoustic propagation attenuation.

The phrase "subscale" is appropriate, since the thrust levels of rockets in the reference database are orders of magnitude lower $(\sim 5-50 \mathrm{kN})$ than the current design thrust for the Ares launch family $(\sim 13 \mathrm{MN})$; thus, extrapolation is needed to extend the various reference curves to match Ares-scale acoustic levels. The use of extrapolation techniques introduces a certain degree of uncertainty to be placed with the acoustic environment prediction. This uncertainty is propagated all the way through to launch vehicle structure qualification level creation. Extrapolation uncertainty can be reduced or eliminated by using free-field noise source spectrums from RSRMV thrust level solid rocket firings. However, before now NASA had never measured plume acoustics from large thrust solid rocket motors on a scope needed to create a new reference database.

Direct acoustic measurements of a large-thrust rocket motor will help assess the current extrapolation process by direct comparison between subscale and full-scale data. The large thrust free-field noise spectrums can also be used directly to update the NASA SP-8072 database and eliminate the need to extrapolate full-scale motor behavior. Extrapolation assessment and database updates can help increase the accuracy of Ares lift-off acoustic environment predictions and ultimately reduce uncertainty associated with structure qualification level creation.

Approximately twice a year, the RSRM prime vendor, ATK Space Systems, static fires an assembled RSRM in a horizontal configuration at its test facility in Utah. The RSRM static firings take place on elevated terrain with the nozzle exit plume mostly undeflected and the landscape allowing placement of microphones within direct line of sight to the exhaust plume. Comparison between the four-segment RSRM and five-segment RSRMV designs show that the thrust levels are close in value for the first half of burn time, so little to no extrapolation is needed to scale measured RSRM acoustic spectra to RSRMV levels. The Ares Program Office sponsored measurement of RSRM plume acoustics for three static tests, designated Technical Evaluation Motor (TEM) - 13, Flight Verification Motor (FVM) - 2, and Flight Support Motor (FSM) - 15. Personnel from ATK Space Systems, Wyle, and MSFC all participated in the RSRM acoustic measurement process. The main objective was to collect acoustic data sufficient to characterize the RSRM as a free-field source. The acquired data were then used to investigate implications to classically used methodology from NASA SP-8072. This paper will cover the actual data acquisition process and character of the measured data.

In Section 2, the measurements of the three rocket firings will be detailed in terms of microphone layout, motor parameters, surrounding terrain, and acquisition hardware used to collect the data. In Section 3, sample spectra at similar locations will be compared between the three firings. Effects of RSRM nozzle vectoring and delivered thrust on the measured data will be shown. Plans for future data analysis will be discussed in Section 4 .

\section{Acoustic Measurements}

\section{A. RSRM Parameters}

Figure 1 shows the overall dimensions of the assembled RSRM design. The RSRM design contains approximately $500,000 \mathrm{~kg}$ of solid propellant in four casting segments, giving a total motor length of $38.4 \mathrm{~m}$. The RSRM motor provides a peak

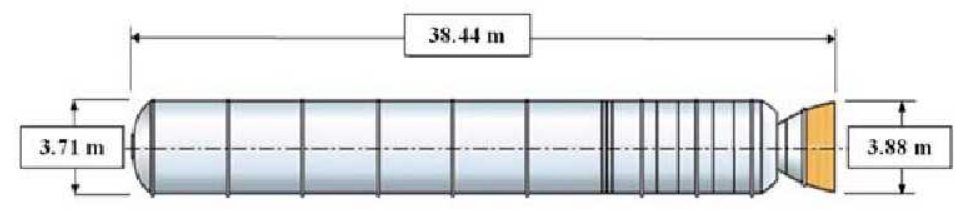

Figure 1. RSRM overall dimensions. 
thrust of 12.9 $\mathrm{MN}$ at sea level while burning for 123 seconds. At maximum thrust, over 5400 $\mathrm{kg}$ of propellant are converted to gas every second and expelled through the nozzle. The estimated thrust and total mass flow rate traces from TEM-13, FVM-2, and FSM15 were all approximately the same as the design RSRM thrust trace. The thrust and mass flow rate traces from all three static tests were averaged and used for data comparison in Section III. These traces are plotted in Fig. 2.

Typically during an RSRM static test, the nozzle is commanded to vector by a test duty cycle. This static test duty cycle is used to check RSRM nozzle performance during operation. The nozzle is canted by a few degrees in multiple orientations with respect to the nozzle axial centerline. FVM-2 and FSM-15 had standard nozzle duty cycles, shown in Fig. 3a. TEM-13 had a non-standard duty cycle, shown in Fig. 3b. The resulting acoustic measurement differences from these two duty cycles will be discussed in Section III.

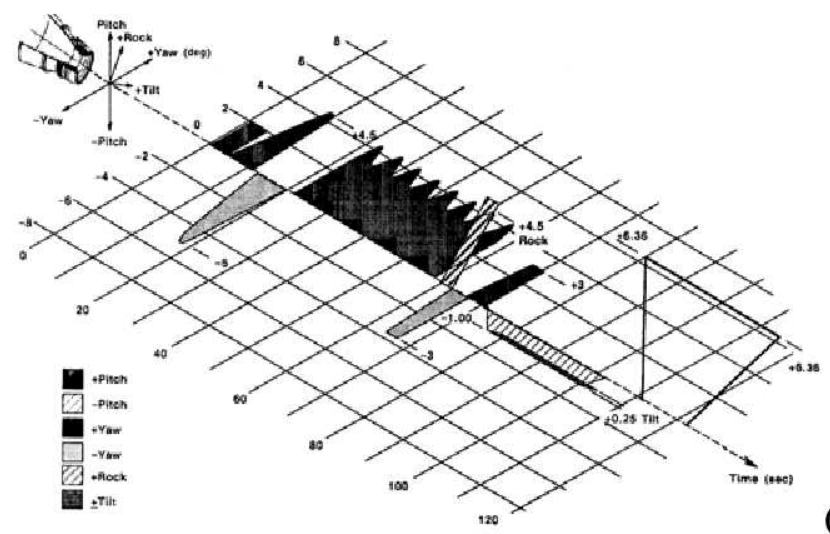

(a)

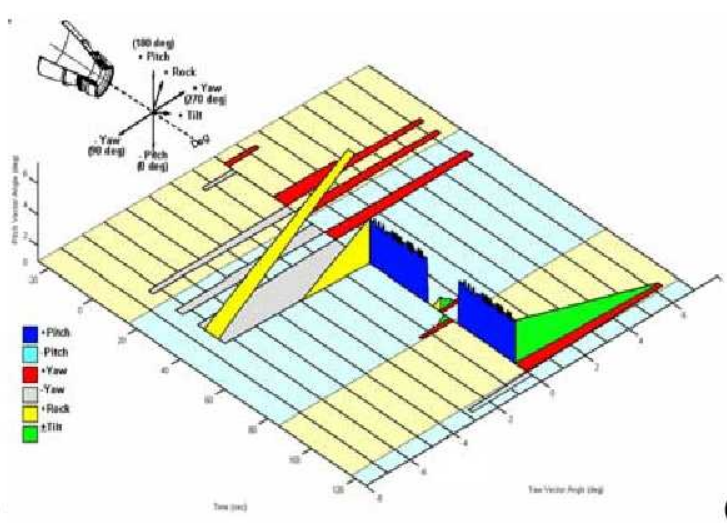

(b)

Figure 3. Nozzle duty cycles $^{3}$ for (a) FVM-2 and FSM-15 and (b) TEM-13.

\section{B. Test Area}

All three static tests were fired at the T-24 test stand at ATK Space Systems in Promontory, Utah. The motor was mounted horizontally and fired towards the mountainside. The distance from the nozzle exit plane to the mountainside was approximately 75 nozzle exit diameters downstream. The terrain was generally level with the test stand for about $70 \mathrm{~m}$ south of the motor centerline, then the elevation began to drop further south. Figure 4 gives elevation contours with respect to the test stand, along with the various microphone locations used for the three tests. The line of fire shown is an extension of the motor axis towards the hill side. The delineated plume boundaries shown are at $21^{\circ}$ with respect to the line of fire. They are an approximation of the angle subtended by the plume plus the maximum yaw of the nozzle during the firing. As can be seen in the figure, the microphones were placed on a 


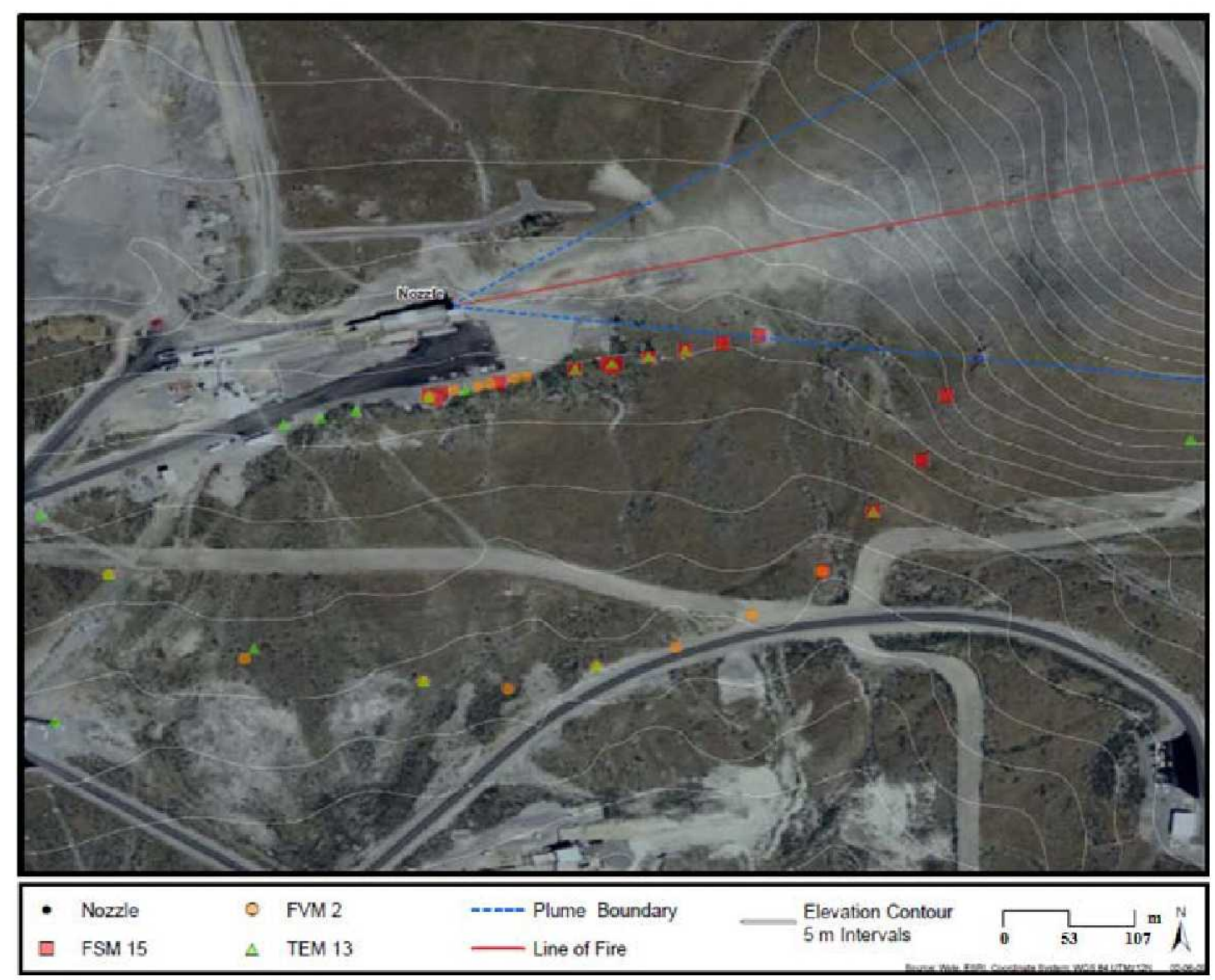

Figure 4. RSRM test area layout and acoustic microphone locations.

line parallel to the motor line to measure the near field acoustic radiation and on a $304 \mathrm{~m}$ arc centered at the nozzle at fixed angles to measure the far field.

\section{Acoustic Acquisition Hardware}

Several microphone and amplifier types were used, depending on the expected noise level and environment at each site. All microphones used were $1 / 4$ inch in diameter. The microphones were oriented vertically on tripods. A picture of the near field array for TEM-13 is shown in Fig. 5. Power modules for the microphones were located at the bases of the tripods. The power modules were connected to the data recorders by coaxial cables. The data recorders were located in a trailer near the lower left-hand corner of Fig. 4.

Data were recorded on two National Instruments PXI chassis containing NI-4472 data acquisition cards. The data were acquired at a rate of 96000 and 48000 samples per second using 24-bit analog to digital converters that employed 64 and 128-times over sampling and low pass filtering to prevent aliasing, respectively.

Meteorological data for the time of firing was recorded for all three firings. For TEM-13 and FVM-2 a portable weather station capable of profiling the atmosphere by measuring wind speed and direction, temperature, and relative humidity at two different heights above the

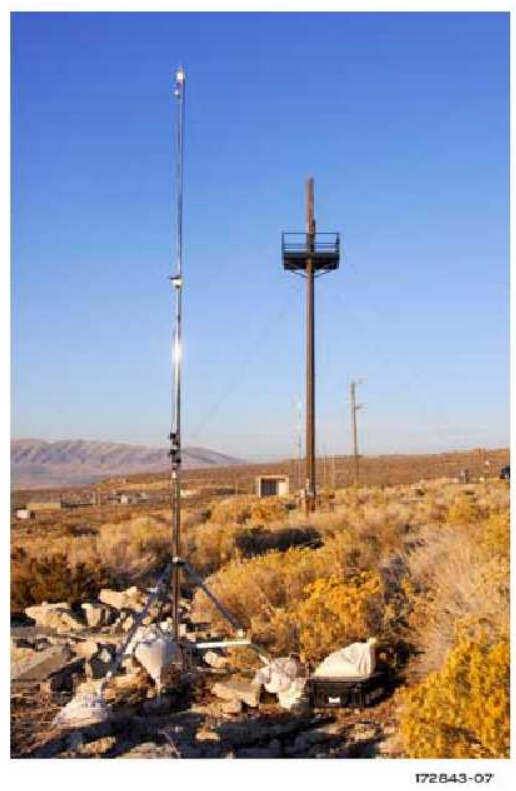

Figure 5. Acoustic microphone tripod setup. 
ground was used. For the FSM-15 firing the data were collected at the T-22 station on the testing grounds by ATK. The relative humidity had to come from another station, but it was assumed to apply throughout the test area. Barometric pressure was also recorded for all three firings.

\section{Procedures}

All systems were assembled in the lab and calibrated for octave band center frequencies from $31.5 \mathrm{~Hz}$ to $16 \mathrm{kHz}$. After deployment in the field, each microphone was calibrated by recording a calibration tone from a piston phone before and after the firing. These recordings along with a barometric correction were used to determine the scaling sensitivity of each microphone system.

The ground impedance was measured using the method outlined in ANSI S1.18-1999. ${ }^{4}$ As there was no apparent variation in soil moisture before and after the three firings, the ground impedance was only measured once for TEM-13 and FVM-2. The same impedance was assumed for FSM-15. The measured ground impedance for all three firings was 160 rayls.

Because some of the microphones deployed in the near field were arranged as a phased array, these microphones were calibrated with a GRAS $50 \mathrm{AB}$ intensity calibrator. The GRAS $50 \mathrm{AB}$ intensity calibrator notes a usable frequency range from 50 to $6300 \mathrm{~Hz}$. This does not mean that the output is flat over this range, it just indicates that the signal seen by each microphone is the same in regards to amplitude and phase. Because of the types of microphones used and the gain settings applied, the usable range for this measurement is reduced to approximately 100 to $6300 \mathrm{~Hz}$. Consider a typical spectrum analyzed from the recording of the intensity calibrator compared to the ambient spectrum, shown in Figs. 6 and 7 respectively. As can be seen band number 19, which corresponds to a center frequency of $80 \mathrm{~Hz}$, is less than $10 \mathrm{~dB}$ above levels shown in the ambient; thus, the level is not sufficiently above the noise floor in that band. Band 20 is highlighted by the cross hatching and shows the necessary $10 \mathrm{~dB}$ of clearance. Band 20 has a center frequency of $100 \mathrm{~Hz}$. Figure 8 shows the transfer function between channels 1 and 2 for a phase calibration recording.

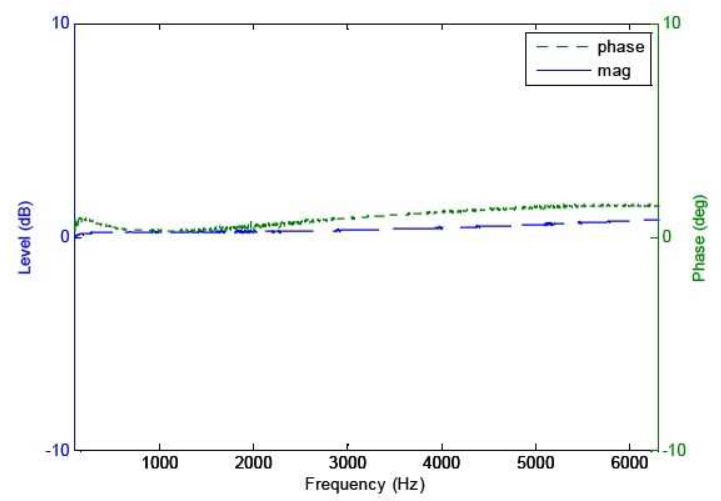

Figure 8. Example magnitude and phase response. 


\section{Data Analysis}

Data collected from the three static tests were analyzed in several different ways. Initially, the measurement time histories were plotted and checked for any discrepancies. The time history plots for each viable measurement are given in the Appendix. The sub-sections below discuss several observations noticed from the data sets. Further data analysis is ongoing to support enhancement of lift-off acoustic prediction tools, but those specific analyses will not be shown in this paper.

\section{A. Character of Time Histories}

Figure 9 gives time histories for measurements $67 \mathrm{~m}$ and $304 \mathrm{~m}$ off of the nozzle exit centerline. The measurement at $304 \mathrm{~m}$ away shows peak-to-peak pressure magnitudes roughly half of the values at the $67 \mathrm{~m}$ measurement location. Both measurements show a general skewness of the data towards positive pressure values. Ref. 5 has shown a similar "characteristic high sidedness" with lift-off acoustic measurements from a series of launch vehicles. It is believed that the nonlinear shock contributions to the plume acoustics are responsible for creating the positive data skewness.
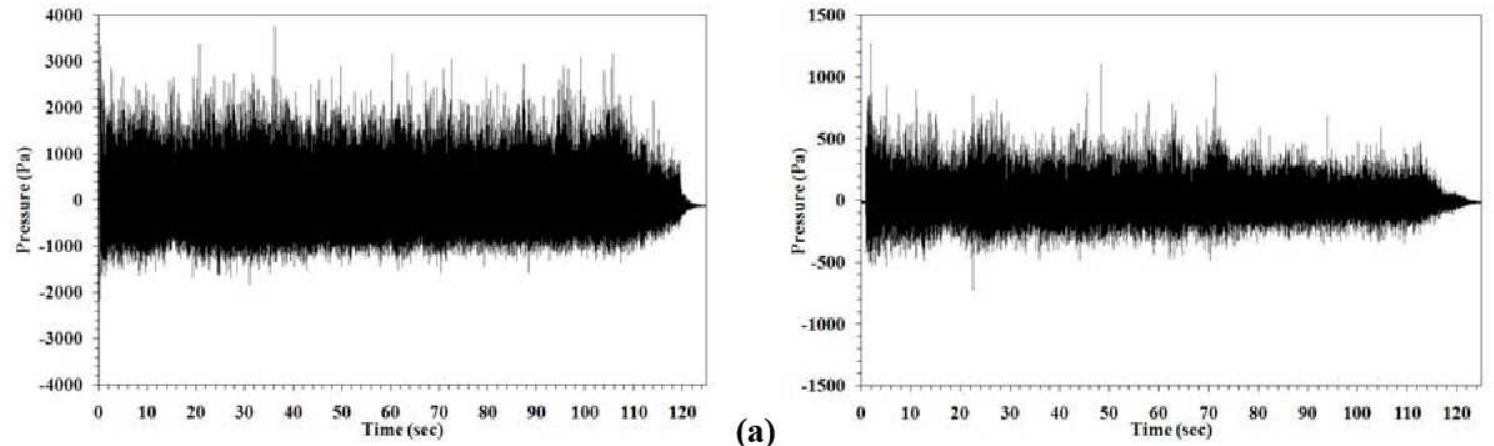

(b)

Figure 9. FVM-2 time histories at $90^{\circ}$ with respect to the nozzle exit plane at radial distances of (a) $67 \mathrm{~m}$ and (b) $304 \mathrm{~m}$.

Figure 10 shows the initial signal readings from the measurements shown in Fig. 9. The time delay between the two measurements' first reading is $692 \mathrm{~ms}$. The ambient conditions during the FVM-2 firing gave an ambient air temperature of $5{ }^{\circ} \mathrm{C}$, an ambient pressure of $85.6 \mathrm{kPa}$, and an ambient relative humidity of $48 \%$. These three readings gave an estimated sound speed of $334.7 \mathrm{~m} / \mathrm{s}$. This sound speed multiplied by the time delay gives an apparent acoustic wave travel distance of $231.6 \mathrm{~m}$, compared to the estimated radial distance between the two measurement locations of $235.9 \mathrm{~m}$.
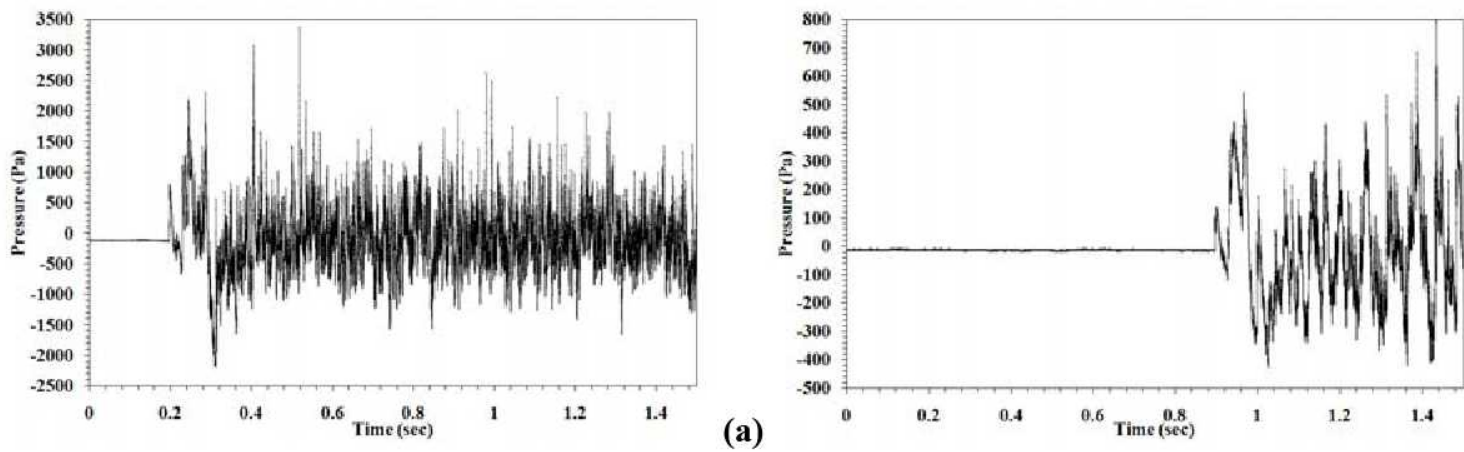

(b)

Figure 10. FVM-2 initial waveforms at $90^{\circ}$ with respect to the nozzle exit plane at radial distances of (a) $67 \mathrm{~m}$ and (b) $304 \mathrm{~m}$. 
The $67 \mathrm{~m}$ measurement's initial wavefront has a large positive increase in pressure, followed by a reduction in pressure to negative values of the same magnitude. The enveloped peak-to-peak range from this initial wavefront is approximately $4.5 \mathrm{kPa}$, which is followed by two more peaks at $0.4 \mathrm{~s}$ and $0.5 \mathrm{~s}$. The initial waveform is considered the blast wave generated by motor ignition. This waveform travels radially outward from the nozzle exit plane, reaching the $304 \mathrm{~m}$ measurement $692 \mathrm{~ms}$ later. The $304 \mathrm{~m}$ measurement shows the same assumed waveform but the initial peak-to-peak value is $1 \mathrm{kPa}$.

Figure 11 gives the same two FVM-2 measurements in the 18-19 s time period where the delivered thrust reaches maximum levels. The $67 \mathrm{~m}$ pressure values give multiple positively skewed pressure values throughout the time period. The pressure values also show how much high frequency content is contained within the measured waveform. The $304 \mathrm{~m}$ measurement also has multiple positively skewed pressure values displayed at lower rates compared to the $67 \mathrm{~m}$ measurement. The lower rate in the $304 \mathrm{~m}$ measurement implies that the associated spectral content has higher amplitudes at lower frequencies compared to the $67 \mathrm{~m}$ measurement.
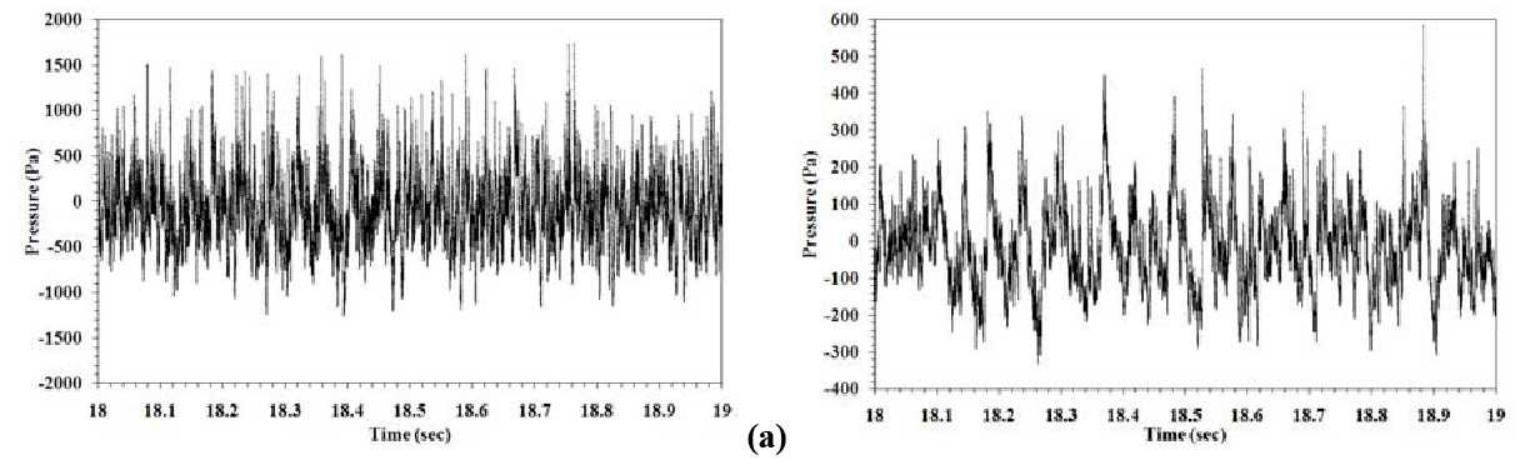

(b)

Figure 11. FVM-2 18 - 19 second waveforms at $90^{\circ}$ with respect to the nozzle exit plane at radial distances of (a) $67 \mathrm{~m}$ and (b) $304 \mathrm{~m}$.

\section{B. Nozzle Vectoring and Thrust Level Effects}

As the motor burns, the thrust level and nozzle vector angle (with respect to the exit centerline) change with time. Referencing Fig. 3a, the largest vector angle deflection in the standard nozzle duty cycle for the first 60 seconds of test time is $5^{\circ}$ in the yaw plane. No pitch or rock commands are given during this time period. Even with motion just in the yaw plane however, the apparent plume noise sources may move enough to cause a change in the measured levels. Additionally, the delivered motor thrust and associated flow stream power changes with time. The overall sound pressure levels were calculated for each measurement and plotted against both the nozzle duty cycle commands and estimated thrust level. Figure 12 gives these overall sound pressure levels for different channels and different tests. The overall sound pressure levels were evaluated using root mean square (RMS) levels calculated over a 1.4 second time window.
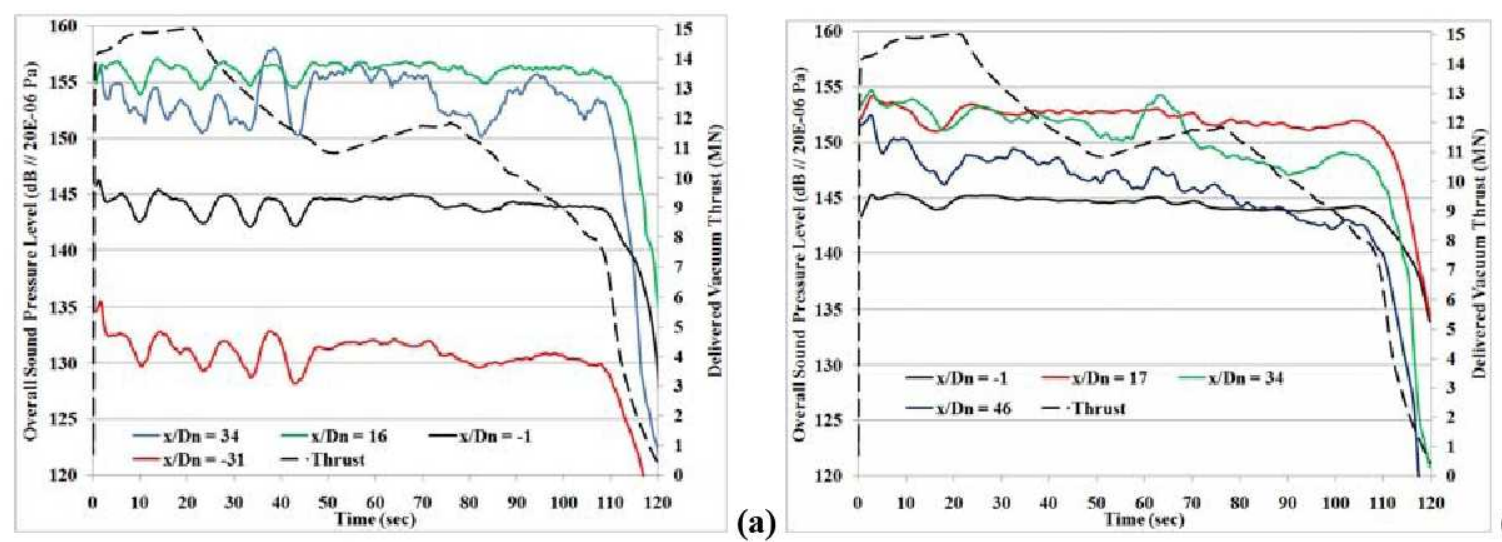

Figure 12. Near-field overall sound pressure levels from (a) TEM-13 and (b) FSM-15. 
The TEM-13 overall sound pressure levels notably changed in time with the nozzle duty cycle commands. Specifically, measured levels varied the first 40 seconds as a result of the large change in nozzle duty cycle stroke commands. Conversely, the FVM-2 and FSM-15 sound pressure levels did not display as much change with the nozzle duty cycle. One difference between the TEM-13 duty cycle and the FVM-2/FSM-15 duty cycle is the increase yaw angle vectoring. The TEM-13 nozzle oscillated between a $+/-6^{\circ}$ yaw angle for the first 30 seconds of firing, while the FVM-2/FSM-15 duty cycle only goes

to $-5^{\circ}$ yaw angle for $10-20$ seconds. TEM-13 also has a linear rock angle command around 40 seconds into firing.

The changing thrust level for the first half of firing seemed to have a lesser effect on measured acoustic levels. The maximum thrust value of 15 $\mathrm{MN}$ reduces by $27 \%$ to $11 \mathrm{MN}$ at 50 seconds. During this time period, the TEM-13 overall sound pressure levels do not decrease nearly as much as when the nozzle was vectoring. FVM-2 and FSM-15 show similar trends of being more sensitive to the nozzle duty cycle than the reduction in thrust. Thrust level effects are better seen towards end of burn at 110 seconds. The sharp thrust decay near the end of motor burn causes a subsequent decay in the overall sound pressure levels for all three data sets.

\section{1/3 Octave Band Spectra}

Comparison of TEM-13, FVM-2, and FSM-15 spectral content is given below in Figs. $13-15$ with one-third octave band spectrums. The time slices chosen for the spectrum analysis give approximately the same nozzle vector angle between the three firings. Since TEM-13 had a different nozzle duty cycle compared to FVM-2 and FSM-15, its spectrum analysis time was slightly different.
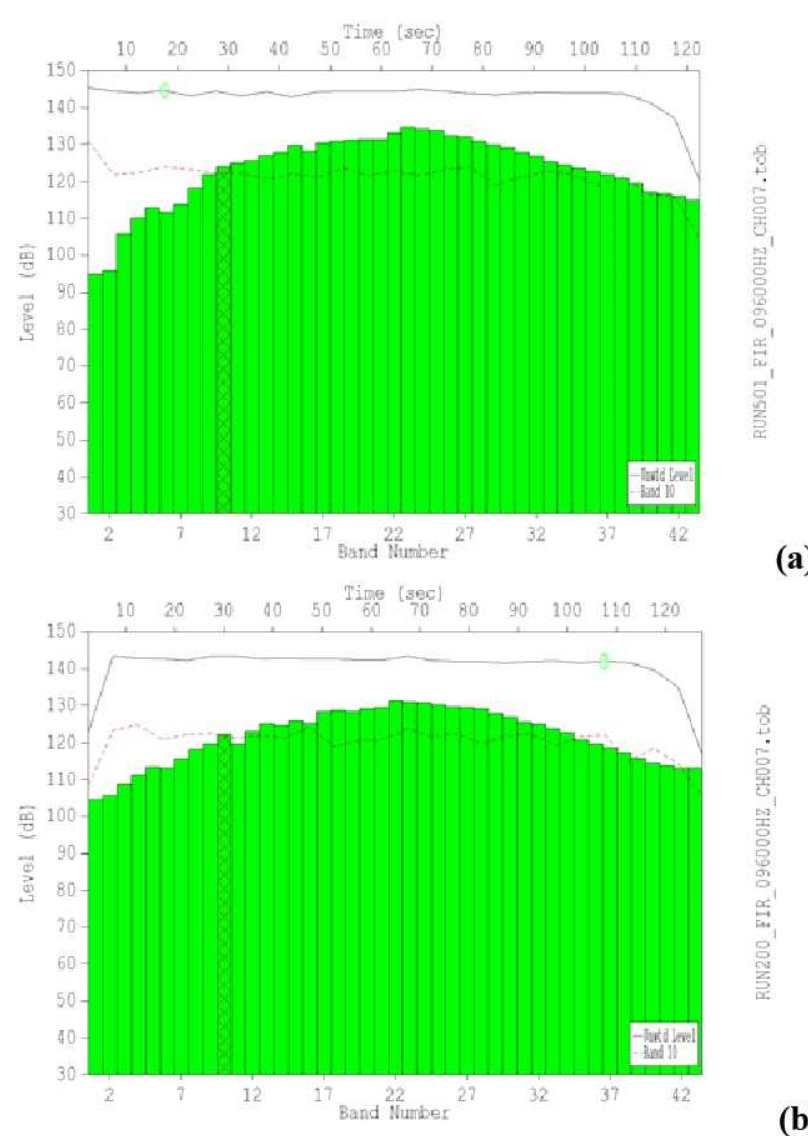

(a)

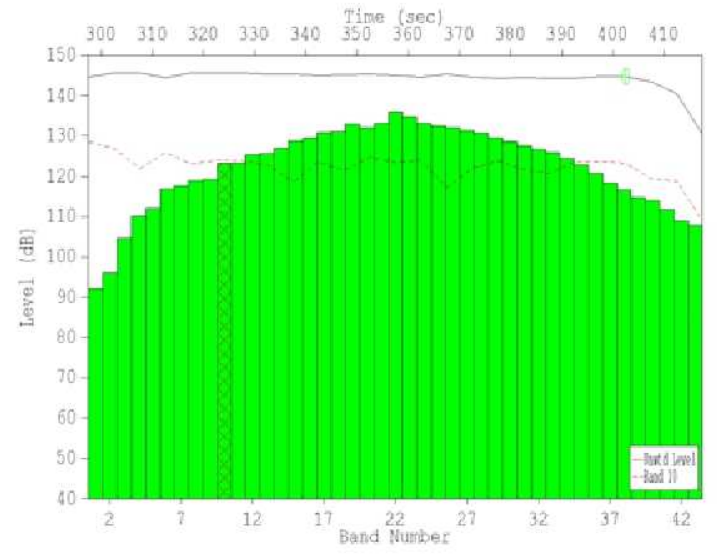

(b)

(c)

Figure 13. Time histories and one-third octave band spectra measured at approximately $67 \mathrm{~m}$ and $90^{\circ}$ off nozzle centerline from static tests (a) TEM-13, (b) FVM2, and (c) FSM-15. 

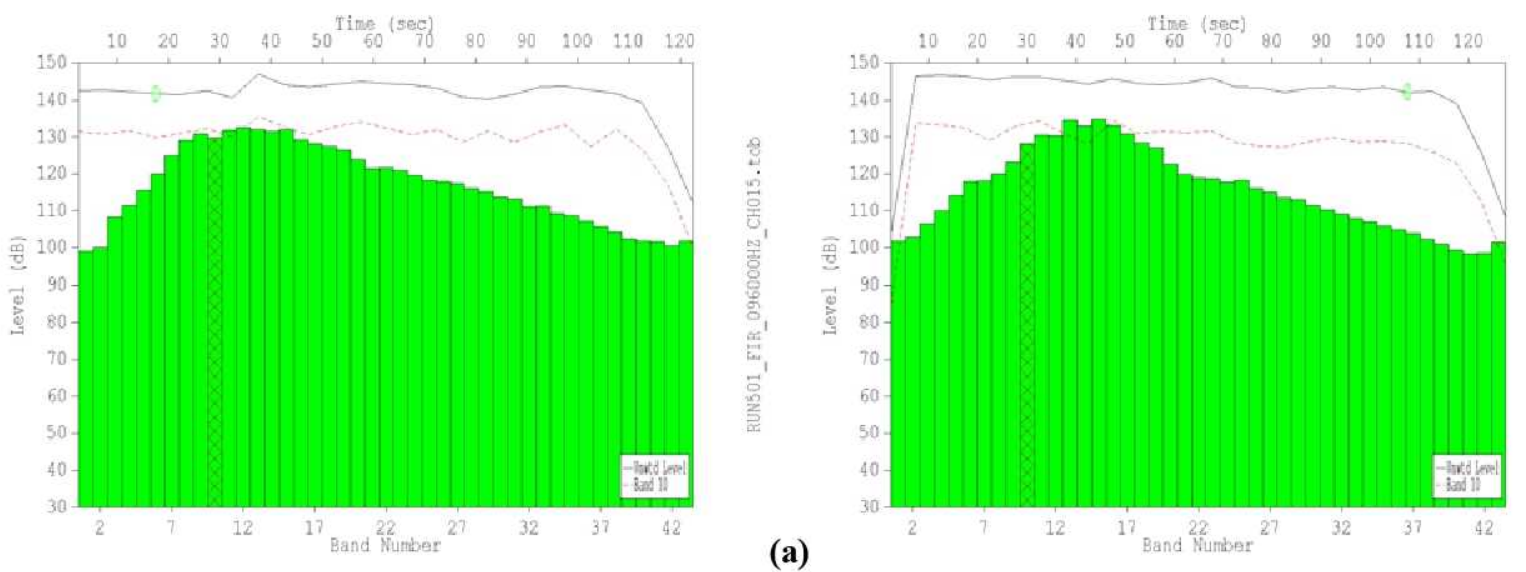

(a)

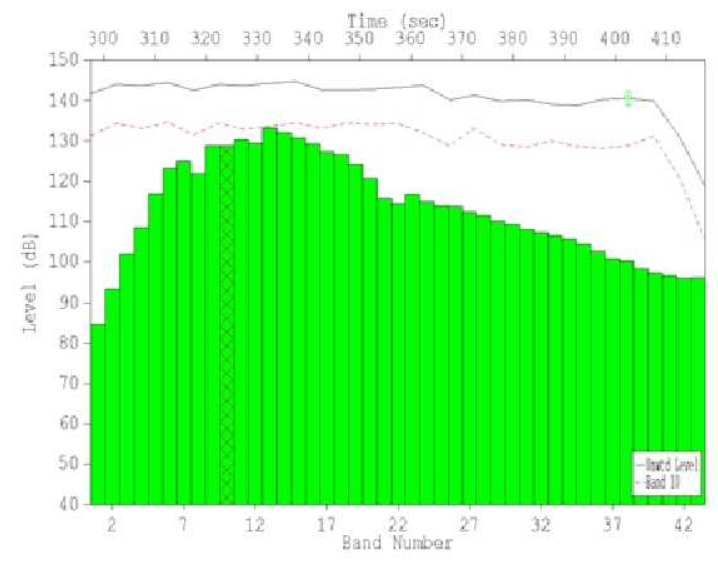

(b)

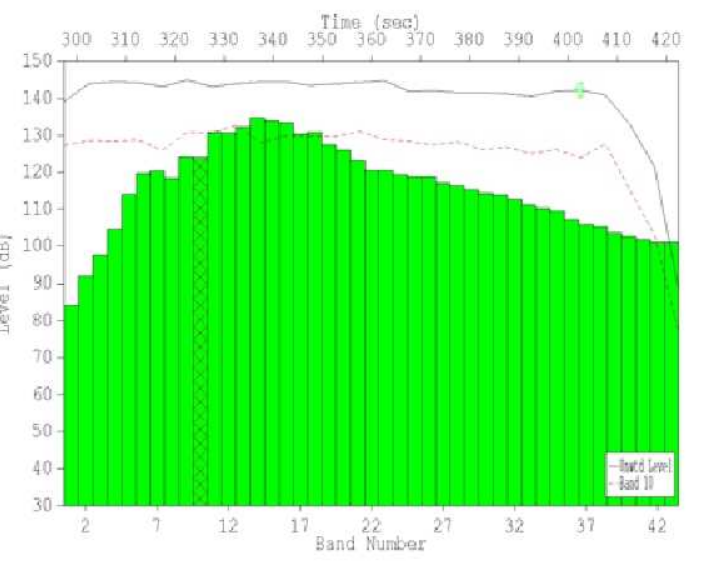

(b)

Figure 14. Time histories and one-third octave band spectra measured at approximately $304 \mathrm{~m}$ and $46^{\circ}$ off nozzle centerline from static tests (a) TEM13 and (b) FSM-15.

Figure 16 shows octave band data from the FVM-2 firing at $304 \mathrm{~m}$ and $90^{\circ}$ with respect to the nozzle centerline. The data shows a decrease in the spectra around the $100 \mathrm{~Hz}$ octave band. The dip was seen in multiple measurement locations and was generally fixed over the firing time. It is believed that the high winds experienced during this firing caused the acoustic radiation "bend" down towards the terrain, setting up a classic destructive interference effect commonly seen with free-field pole measurements. The wind levels were not as high during the TEM-13 and FSM-15 firings, so the 100 $\mathrm{Hz}$ destructive interference effect was not displayed in the data.

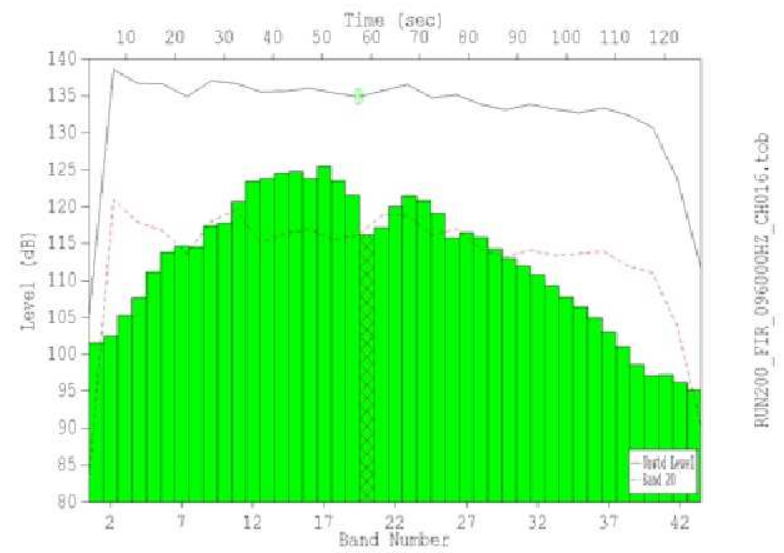

Figure 16. FVM-2 time history and one-third octave band spectra measured at approximately 304 $\mathrm{m}$ and $90^{\circ}$ off nozzle centerline. 


\section{Spatial Distribution of Sound Pressure Levels}

The FSM-15 firing had the most near-field acoustic measurements of all three static firings. Twenty-seven microphones were placed approximately $67 \mathrm{~m}$ off-axis and parallel to the motor's thrust centerline. 20 of these microphones were localized into two groups of "T-arrays" to be used for time domain beamforming for apparent plume noise source location. The other seven microphones were spaced along the $67 \mathrm{~m}$ off-axis line starting near the motor nozzle exit plane and ending roughly 50 nozzle diameters downstream. These seven microphones were used to investigate the near-field distribution of sound downstream of the nozzle exit plane. Figure 17 shows the measured overall sound pressure levels at each near-field spatial location for three different time periods in the FSM-15 test. The $\mathrm{x}$-axis is normalized by the RSRM nozzle exit diameter.

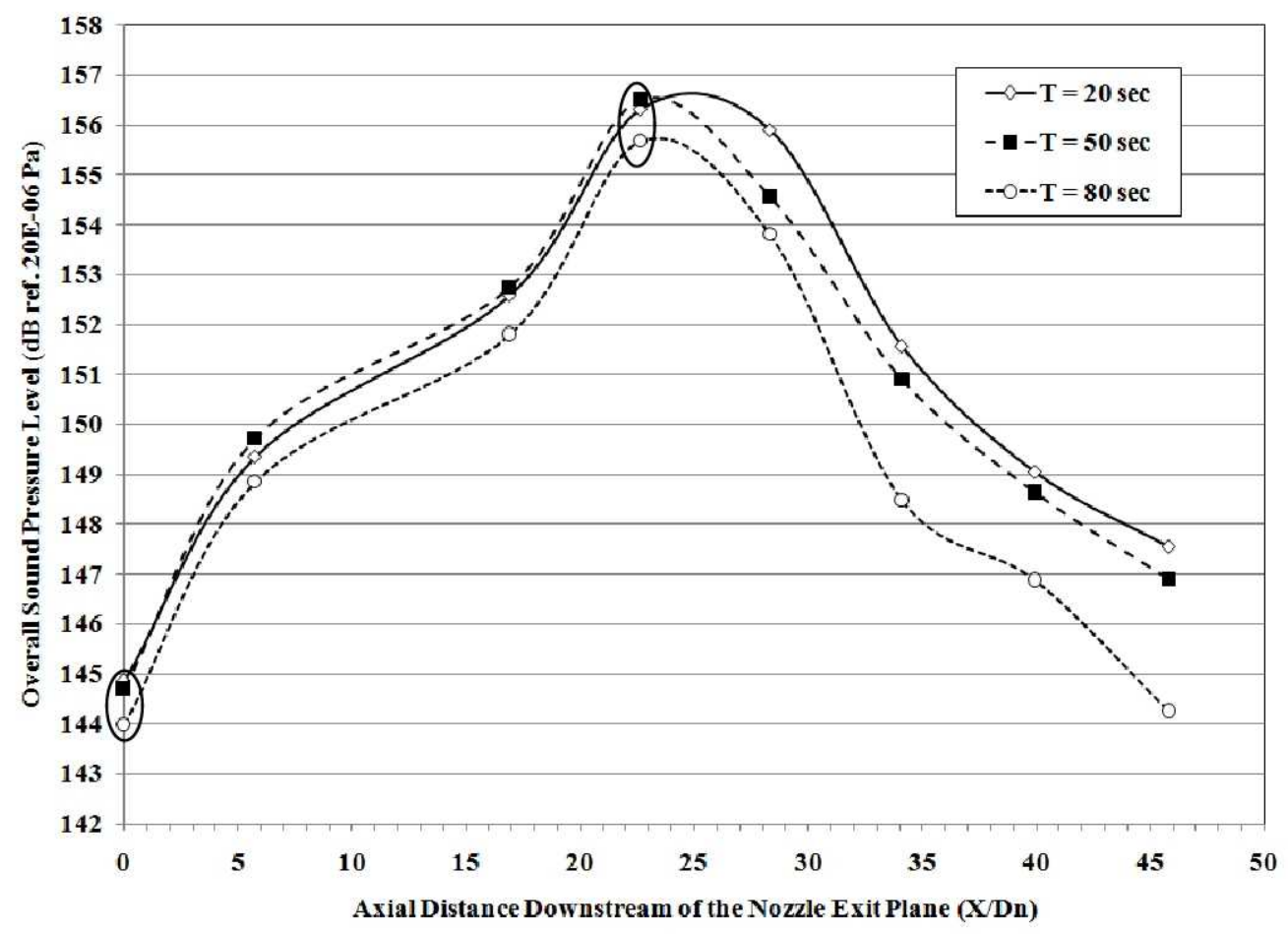

Figure 17. FSM-15 near-field overall sound pressure level spatial distributions for three different test times. Circled values are from spatially averaged measurements taken at the T-arrays.

Figure 17 shows that the peak sound pressure levels occur between 20-30 nozzle exit diameters downstream of the exit plane. Highest peak levels are seen at 20 seconds when the motor thrust is maximum. The levels then drop for later test times of 50 and 80 seconds, but the general spatial dependence of sound pressure level stays the same. The peak sound pressure levels seem to move closer to 23 nozzle exit diameters downstream throughout the test. Future work with the T-array measurements will help better locate the apparent peak in the 20-30 nozzle exit diameter range. It is interesting to note that the general trend of sound pressure level dependence with downstream location stays approximately the same for each curve until the peak level is reached. After the peak level, the decay of sound pressure level with downstream location increases for later test times. 
Figure 18 gives the far field overall sound pressure levels calculated at 50 seconds into the firing. The data values are taken from both the FVM-2 and FSM-15 measurements to give a fuller range of measurement angles. The measurement locations are oriented with respect to the average nozzle centerline in the 50 second time period. It appears that the peak overall sound pressure level occurs at approximately $50^{\circ}$ with respect to the nozzle centerline. Other firing times show that the peak overall sound pressure level stays at approximately $50^{\circ}$.

\section{Summary and Future Work}

Collaboration between NASA, Wyle Labs, and ATK Space Systems has successfully generated NASA's first large-scale solid rocket motor plume acoustic data set. The data set includes near and far field acoustic measurements that will be used to update NASA lift-off acoustic prediction models. The character of the data showed some agreement with previously measured lift-off data from solid rocket motor boosted launch vehicles. Influence of the nozzle duty cycle and changing thrust levels were seen in the data. Overall sound pressure levels gave the peak far field directivity lobe at approximately $50^{\circ}$ with respect to the nozzle centerline.

The data collected will be used to support Ares launch vehicle lift-off acoustic predictions. Several groups are working with the data to incorporate it into predictive plume acoustic models. The reader is encouraged to investigate two works to see how this data impacts current plume acoustic models. These two works are: (1) an updated NASA SP-8072 prediction from NASA-Marshall Space Flight Center ${ }^{6}$, and (2) a launch pad lift-off predictions from Wyle Labs?

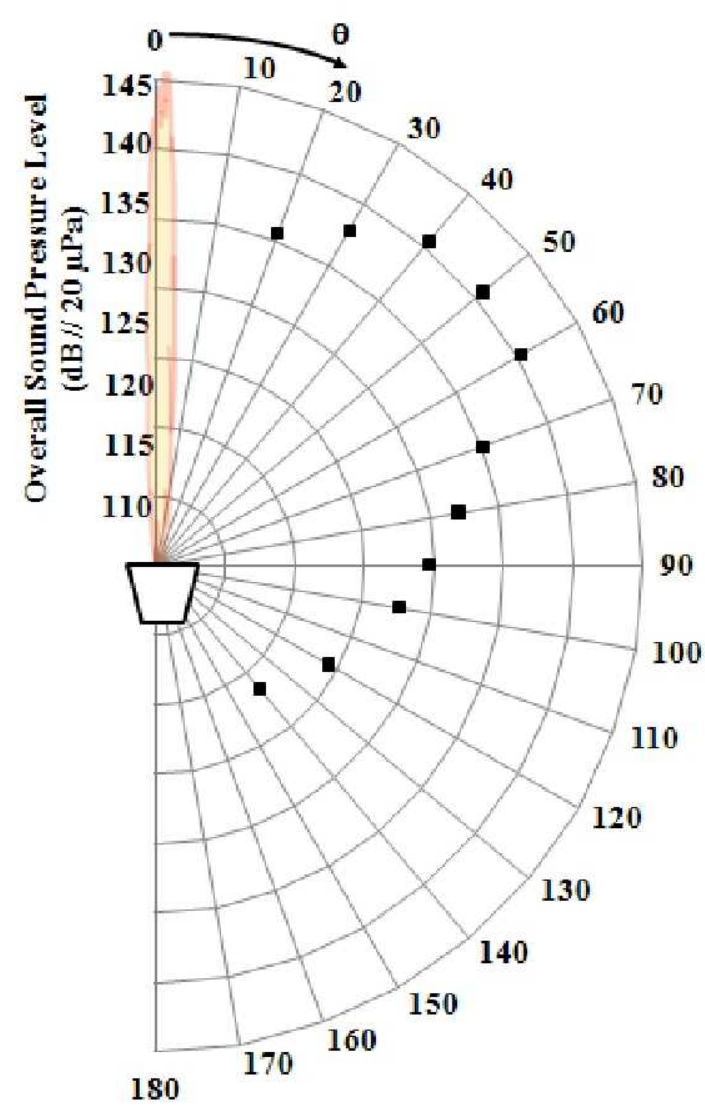

Figure 18. Far-field overall sound pressure level spatial distributions at $50 \mathrm{sec}$ into the firing.

\section{Acknowledgments}

Programmatic support was given by the Ares I Vehicle Integration and First Stage Project Offices, as well as the RSRM Project Office. Facility support was reliably provided by Sam Vigil and the rest of the ATK Space System's Test Area personnel. The following personnel from ATK, Wyle, and MSFC were involved in gathering this acoustic data. Their support is greatly appreciated.

\section{ATK Space Systems \\ - Mike Oksness \\ - Brad Allred \\ - Gerald Leavitt \\ - Tora Rhodes}
$\underline{\text { Wyle }}$
- Roberta Zimmerman
- Ben Manning
- Troy Schultz
- Juliet Page 


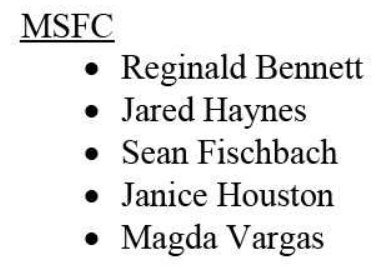

\section{References}

${ }^{1}$ Singer, C.E., Dumbacher, D.L., Lyles, G.M., and Onken, J.F., "NASA's Ares I and Ares V Launch Vehicles-Effective Space Operations Through Efficient Ground Operations," AIAA Paper 2008-3563.

${ }^{2}$ Eldred, K.M., "Acoustic Loads Generated by the Propulsion System," NASA SP-8072, June 1971.

${ }^{3}$ Hughes, P. D., "Space Shuttle Flight Support Motor No. 1 (FSM-1) Final Test Report," Thiokol Corporations, TWR-50068, November, 1990.

${ }^{4}$ Acoustical Society of America National Standard, "American National Standard Template Method for Ground Impedance," ANSI S1.18-1999.

${ }^{5}$ McInerny, S.A., "Launch Vehicle Acoustics Part 1: Overall Levels and Spectral Characteristics," Journal of Aircraft, Vol. 33, No. 3, 1996, pp. $511-517$.

${ }^{6}$ Haynes, J., "Ares I Lift-off Environment Predictions Using NASA SP-8072 Distributed Source Method II," AIAA Paper 2009-3160, May 2009.

${ }^{7}$ Plotkin, K., "Lift-off Acoustics Predictions for the Ares I Launch Pad," AIAA Paper 2009-3163, May 2009.

${ }^{8}$ Owen, M., "A Semi-Empirical Jet Noise Model Derived Using the Energy Spectrum," AIAA Paper 2009-3164, May 2009.

\section{Appendix}

This appendix gives the measurement locations and time histories for all three static tests. Time histories are maximum and minimum values reported in $0.3 \mathrm{~ms}$ time intervals.

Table A1. Microphone channel descriptions for the TEM-13 Firing.

\begin{tabular}{|c|c|c|c|c|}
\hline Motor & Channel & Position & $\begin{array}{l}\text { Radial Distance from } \\
\text { Nozzle Exit Origin (m) }\end{array}$ & $\begin{array}{l}\text { Angle From Nozzle } \\
\text { Centerline Axis (deg) }\end{array}$ \\
\hline TEM13 & 1 & Near-Field & 147 & 26 \\
\hline TEM13 & 2 & Near-Field & 127 & 31 \\
\hline TEM13 & 3 & Near-Field & 109 & 38 \\
\hline TEM13 & 4 & Near-Field & 92 & 46 \\
\hline TEM13 & 7 & Near-Field & 69 & 95 \\
\hline TEM13 & 8 & Near-Field & 75 & 112 \\
\hline TEM13 & 10 & Near-Field & 102 & 136 \\
\hline TEM13 & 11 & Near-Field & 120 & 143 \\
\hline TEM13 & 12 & Near-Field & 139 & 148 \\
\hline TEM13 & 13 & Far-Field & 412 & 137 \\
\hline TEM13 & 15 & Far-Field & 306 & 45 \\
\hline TEM13 & 17 & Far-Field & 304 & 85 \\
\hline TEM13 & 18 & Far-Field & 303 & 105 \\
\hline TEM13 & 19 & Far-Field & 301 & 125 \\
\hline TEM13 & 20 & Far-Field & 299 & 146 \\
\hline TEM13 & 21 & Far-Field & 299 & 158 \\
\hline TEM13 & 22 & Far-Field & 463 & 26 \\
\hline TEM13 & 23 & Far-Field & 412 & 137 \\
\hline
\end{tabular}




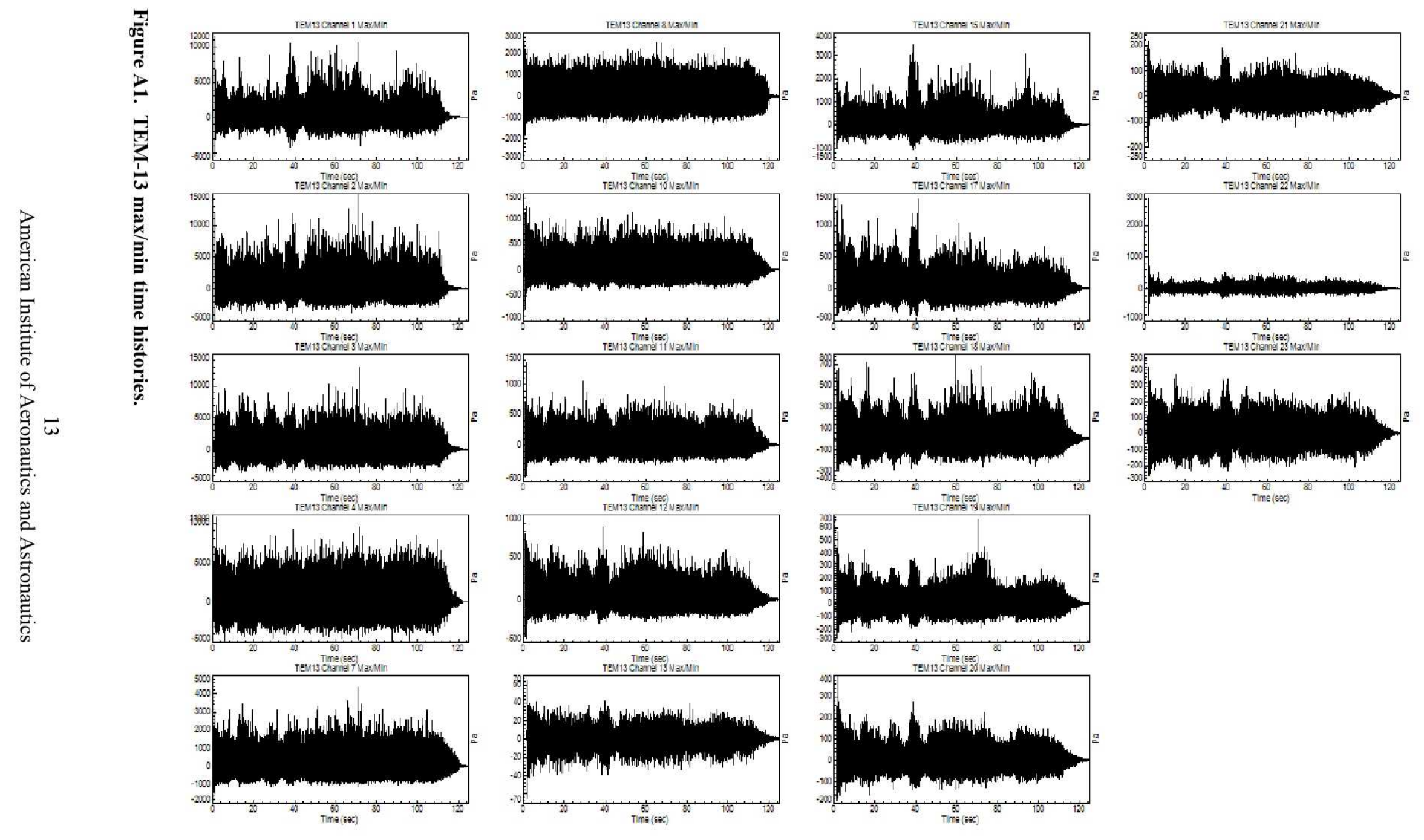


Table A2. Microphone channel descriptions for the FVM-2 Firing.

\begin{tabular}{|c|c|c|c|c|}
\hline Motor & Channel & Position & $\begin{array}{c}\text { Radial Distance from } \\
\text { Nozzle Exit Origin (m) }\end{array}$ & $\begin{array}{c}\text { Angle From Nozzle } \\
\text { Centerline Axis (deg) }\end{array}$ \\
\hline FVM2 & 0 & Near-Field & 74 & 63 \\
\hline FVM2 & 1 & Near-Field & 74 & 63 \\
\hline FVM2 & 2 & Near-Field & 71 & 68 \\
\hline FVM2 & 4 & Near-Field & 68 & 81 \\
\hline FVM2 & 5 & Near-Field & 68 & 100 \\
\hline FVM2 & 7 & Near-Field & 69 & 111 \\
\hline FVM2 & 9 & Near-Field & 75 & 56 \\
\hline FVM2 & 13 & Far-Field & 312 & 66 \\
\hline FVM2 & 14 & Far-Field & 310 & 76 \\
\hline FVM2 & 15 & Far-Field & 308 & 86 \\
\hline FVM2 & 16 & Far-Field & 305 & 96 \\
\hline FVM2 & 17 & Far-Field & 311 & 106 \\
\hline FVM2 & 18 & Far-Field & 312 & 126 \\
\hline FVM2 & 19 & Far-Field & 311 & 146 \\
\hline FVM2 & 20 & Far-Field & 311 & \\
\hline
\end{tabular}



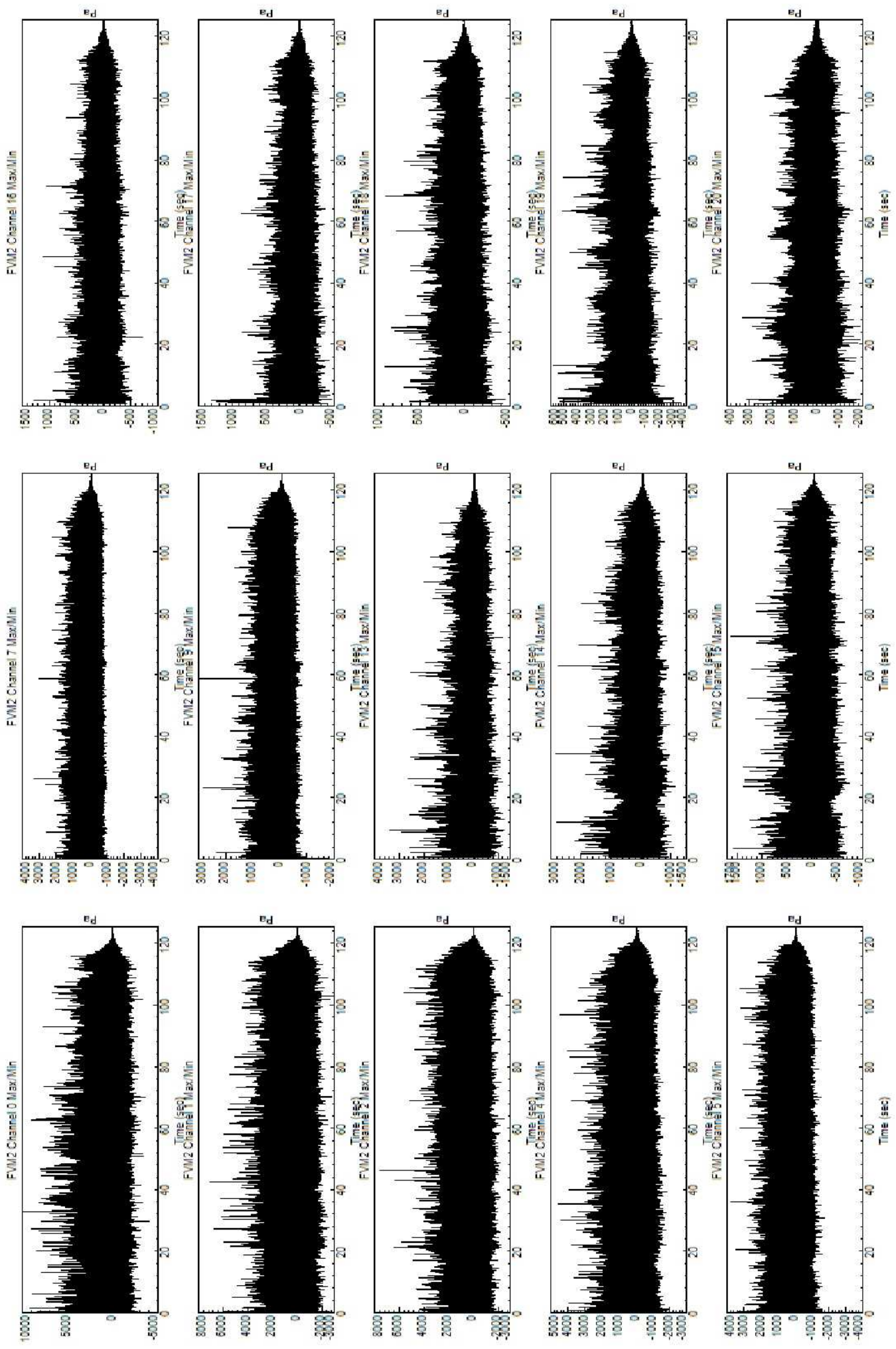

Figure A2. FVM-2 max/min time histories. 
Table A3. Microphone channel descriptions for the FSM-15 Firing.

\begin{tabular}{|c|c|c|c|c|}
\hline Motor & Channel & Position & $\begin{array}{c}\text { Radial Distance from } \\
\text { Nozzle Exit Origin (m) }\end{array}$ & $\begin{array}{c}\text { Angle From Nozzle } \\
\text { Centerline Axis (deg) }\end{array}$ \\
\hline FSM15 & 1 & Near-Field & 70 & 95 \\
\hline FSM15 & 2 & Near-Field & 70 & 94 \\
\hline FSM15 & 3 & Near-Field & 70 & 93 \\
\hline FSM15 & 4 & Near-Field & 70 & 92 \\
\hline FSM15 & 5 & Near-Field & 69 & 92 \\
\hline FSM15 & 6 & Near-Field & 69 & 91 \\
\hline FSM15 & 7 & Near-Field & 69 & 90 \\
\hline FSM15 & 8 & Near-Field & 71 & 92 \\
\hline FSM15 & 9 & Near-Field & 72 & 92 \\
\hline FSM15 & 10 & Near-Field & 73 & 92 \\
\hline FSM15 & 12 & Near-Field & 107 & 37 \\
\hline FSM15 & 17 & Near-Field & 111 & 36 \\
\hline FSM15 & 20 & Near-Field & 111 & 38 \\
\hline FSM15 & 21 & Near-Field & 70 & 71 \\
\hline FSM15 & 23 & Near-Field & 92 & 45 \\
\hline FSM15 & 24 & Near-Field & 127 & 31 \\
\hline FSM15 & 25 & Near-Field & 147 & 26 \\
\hline FSM15 & 26 & Near-Field & 168 & 23 \\
\hline FSM15 & 27 & Near-Field & 189 & 20 \\
\hline FSM15 & 28 & Far-Field & 310 & 26 \\
\hline FSM15 & 29 & Far-Field & 312 & 36 \\
\hline FSM15 & 30 & Far-Field & 306 & 46 \\
\hline FSM15 & 31 & Far-Field & 312 & 56 \\
\hline
\end{tabular}



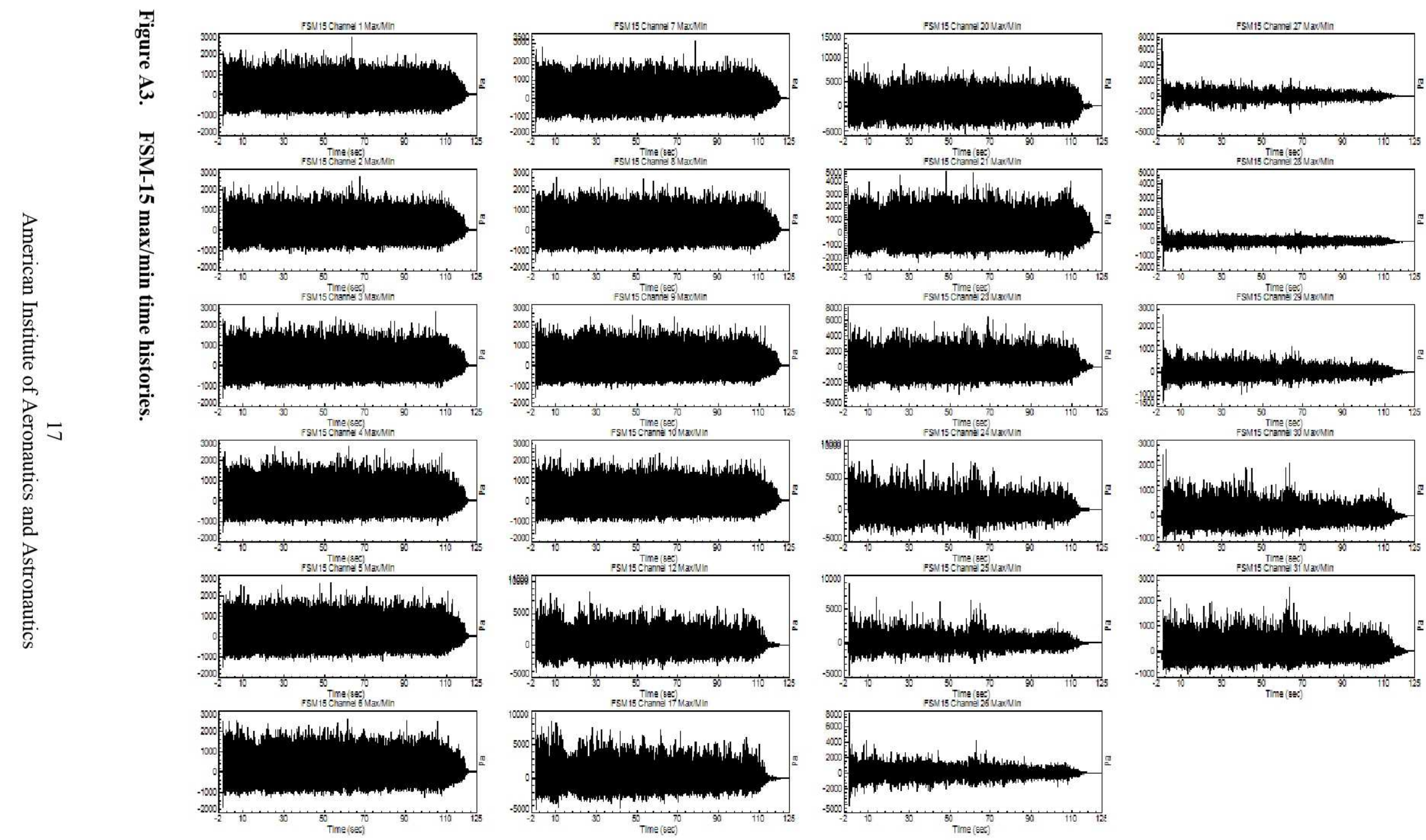


\title{
Measurement and Characterization of Space Shuttle Solid Rocket Motor Plume Acoustics
}

\section{AIAA Aeroacoustics Conference}

\author{
R. Jeremy Kenny \\ Marshall Space Flight Center
}

Chris Hobbs and Ken Plotkin

Wyle Laboratories

Debbie Pilkey

ATK Space Systems 


\section{Outline}

- Background

- Objective

- Results

- Summary and Future Work 


\section{Background}

- NASA currently developing Ares I and Ares $V$ launch vehicles

- Part of design process involves assessment of induced vehicle vibration levels from lift-off acoustics

- High lift-off acoustic vibration levels can drive vehicle structures' qualification levels

- High qualification levels can lead to expensive mitigation solutions

- Structure isolation

- Launch pad sound suppression
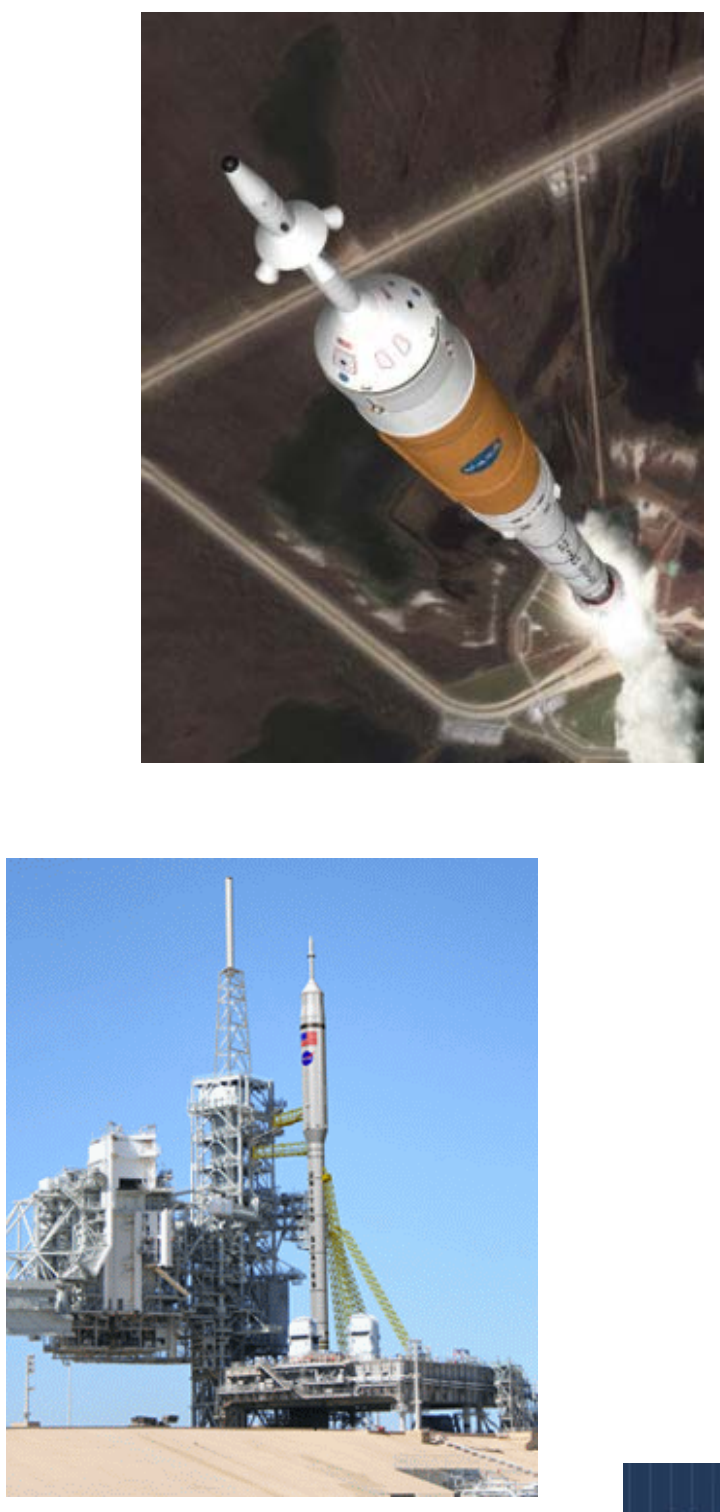


\section{Lift-off Acoustics}

- Best lift-off acoustic environment predictions are needed to yield the best vehicle structure qualification levels

- Lift-off Environment Acoustic Inputs

- Motor plume sound sources and radiation

- Launch pad sound reflections

- Launch pad deflector effects

- Water suppression effects

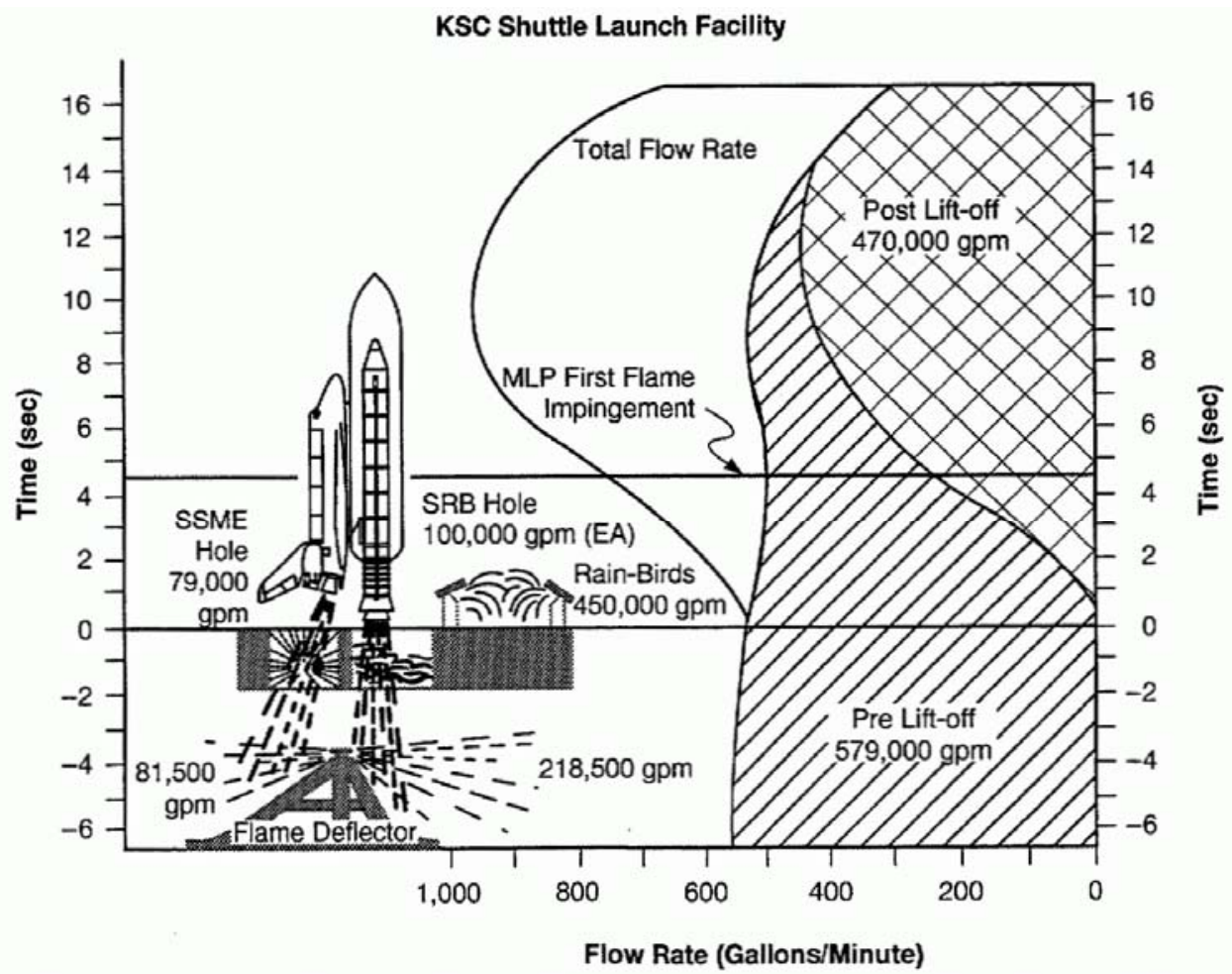

Fig. 50: Total water flow rates for overall suppression system - acoustic and overpressure.

Jones, J.H., Guest, S.H., Nesman, T.E., Matienzo, J.J., and Reed, D.K., "Acoustic, Overpressure, and Unsteady Flow Phenomena Associated with Saturn/Space Shuttle Systems: A Review of Selected Issues," Dec. 1993. 


\section{Available Acoustic Databases}

- Available databases for solid rocket motor plume acoustics limited to subscale tests

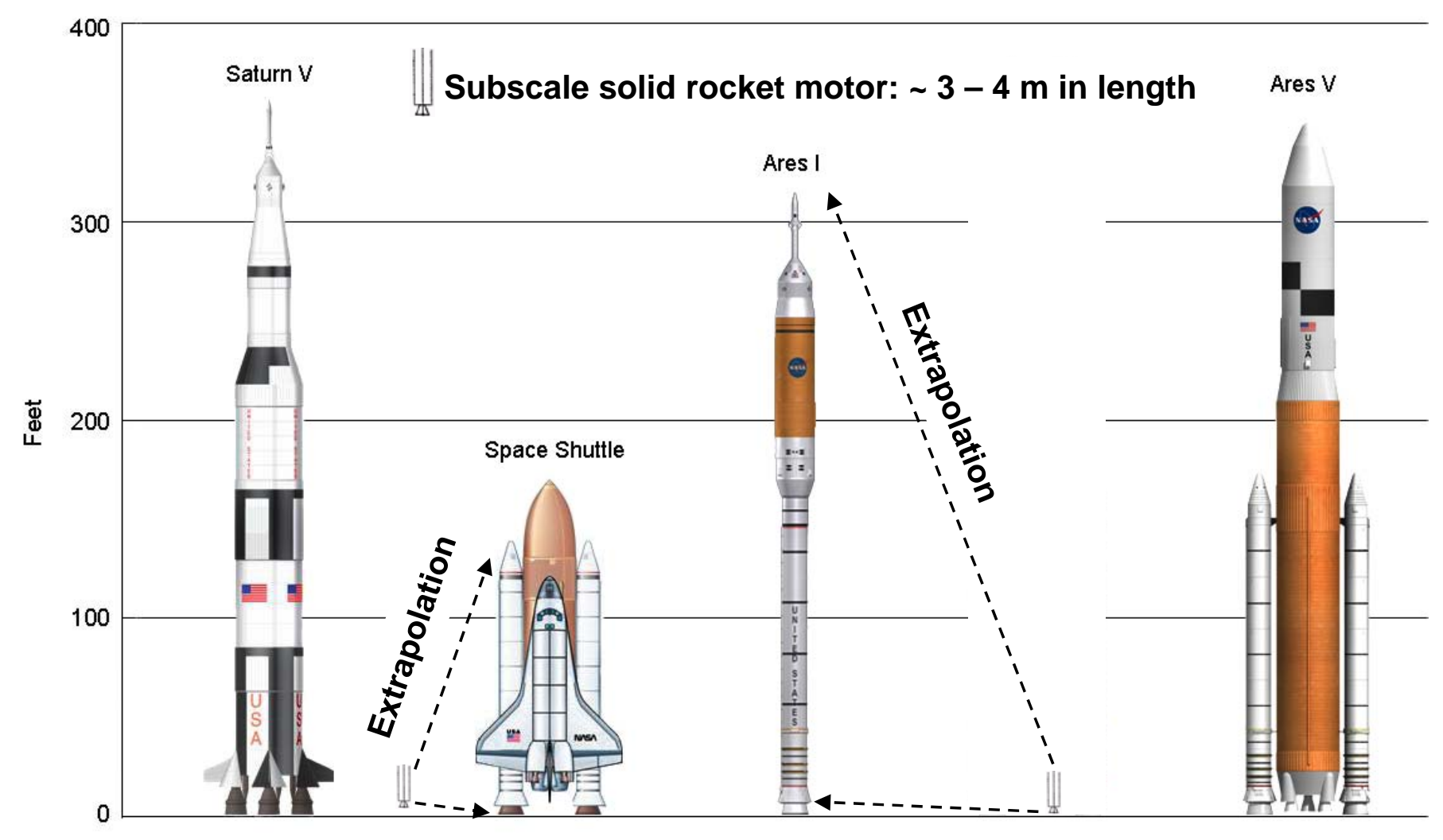

- Scaling/extrapolation introduces error in acoustic predictions 


\section{Objective}

- Omit need for scaling/extrapolation in lift-off acoustic predictions

- Compare measured full scale rocket acoustics to previously measured database

- Achieved through acoustic measurements during Space Shuttle solid rocket motor static tests

- Made successful by partnership between NASA, ATK, and Wyle Labs
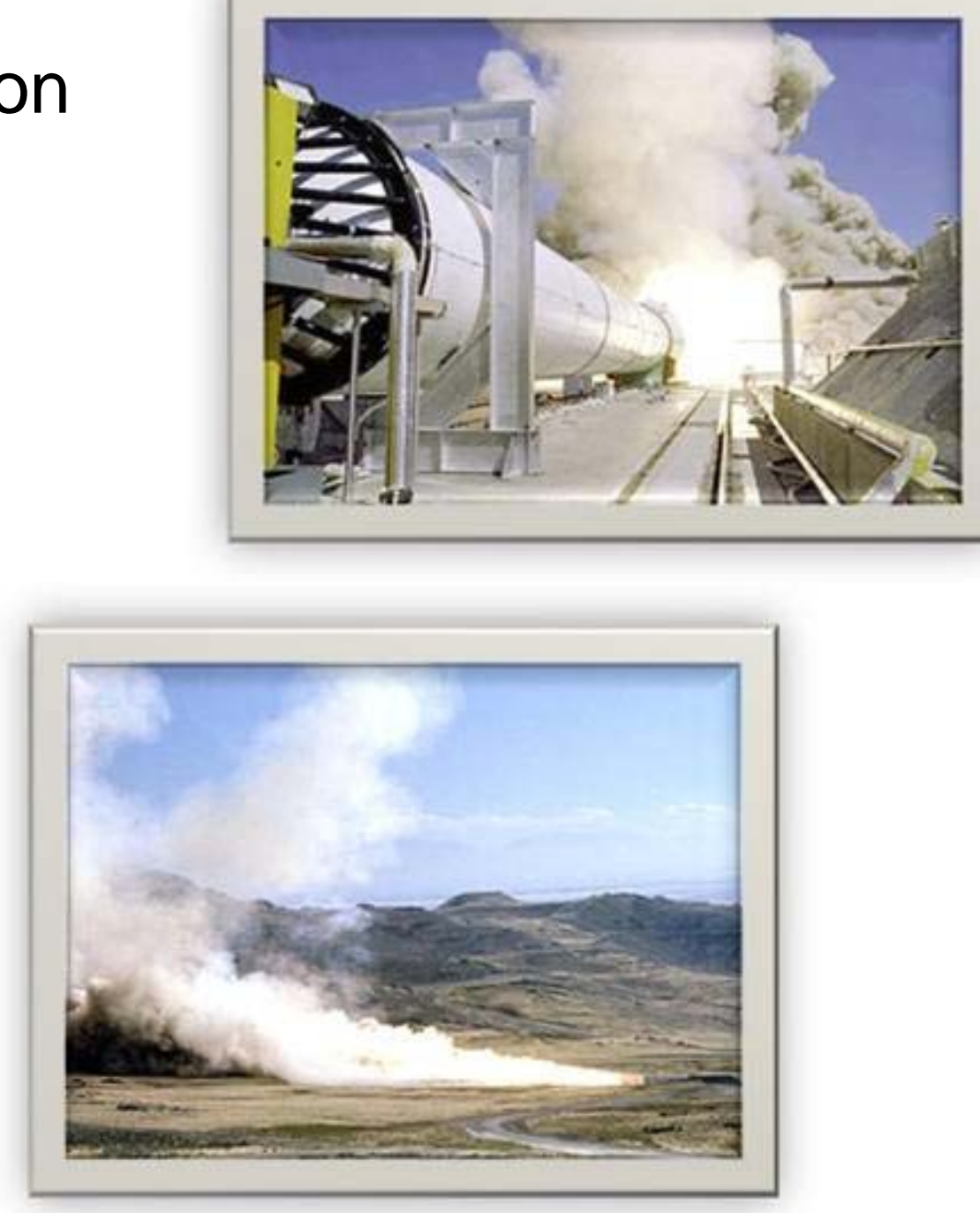


\section{Space Shuttle Motor Tests}

\section{- Reusable Solid Rocket Motor (RSRM)}

- Thrust and nozzle diameter comparable to current Ares I booster design

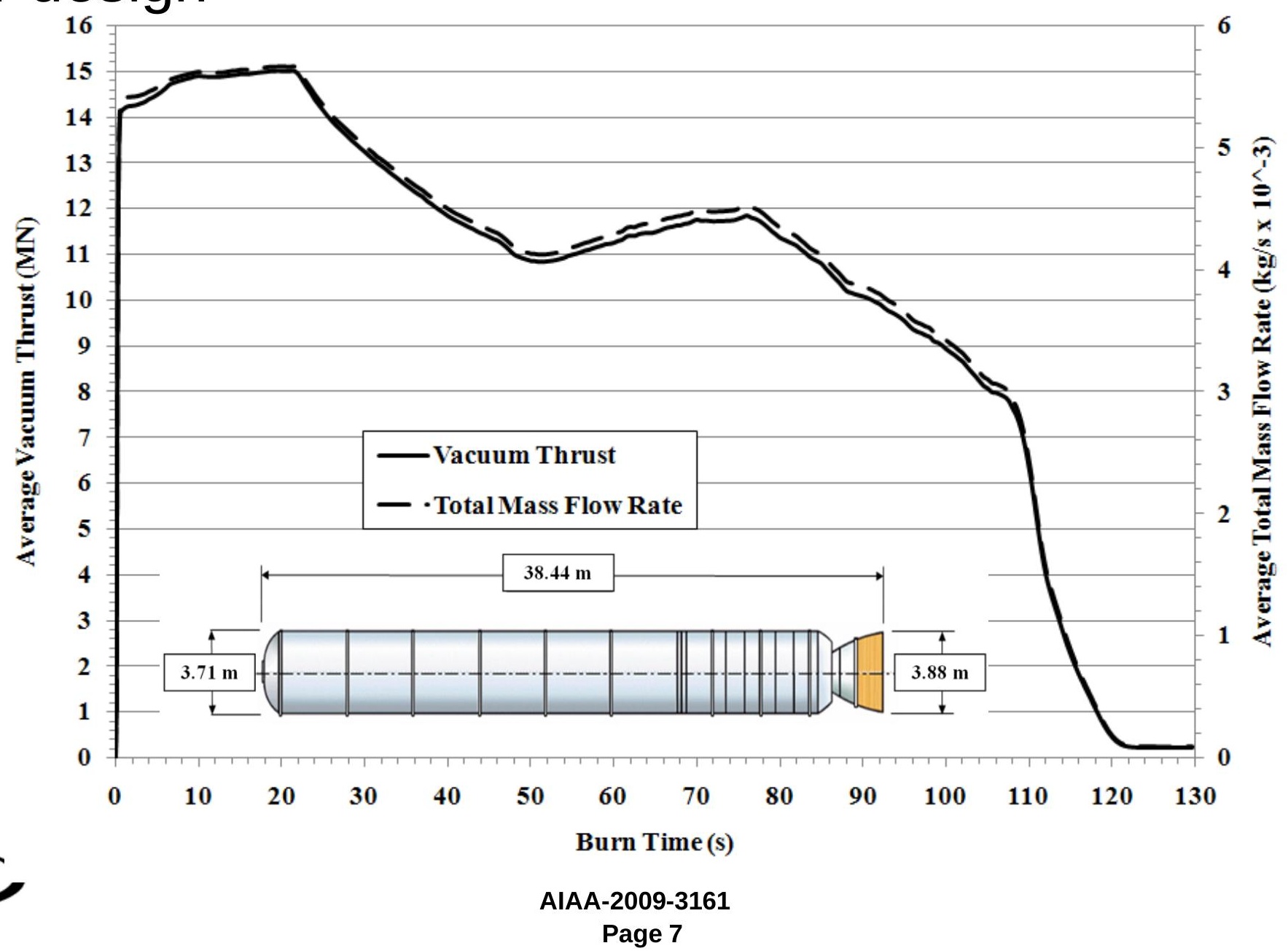


- Technical Evaluation Motor (TEM)-13: 23 Microphones

- Flight Verification Motor (FVM)-2: 20 Microphones

- Flight Support Motor (FSM)-15: 31 Microphones

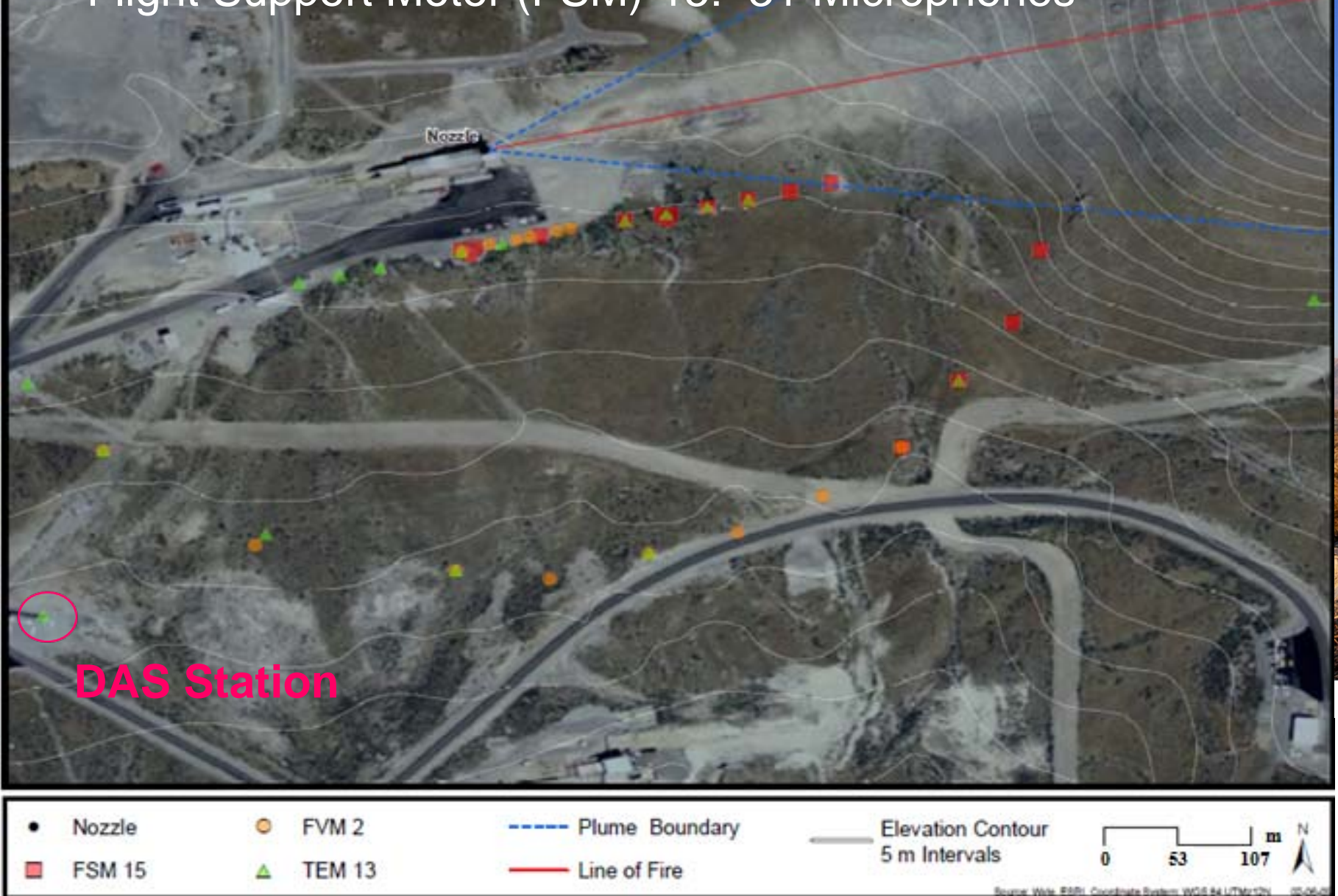




\section{Example Time Histories}

- Positive skewness of data

- Potentially due to plume shock contributions

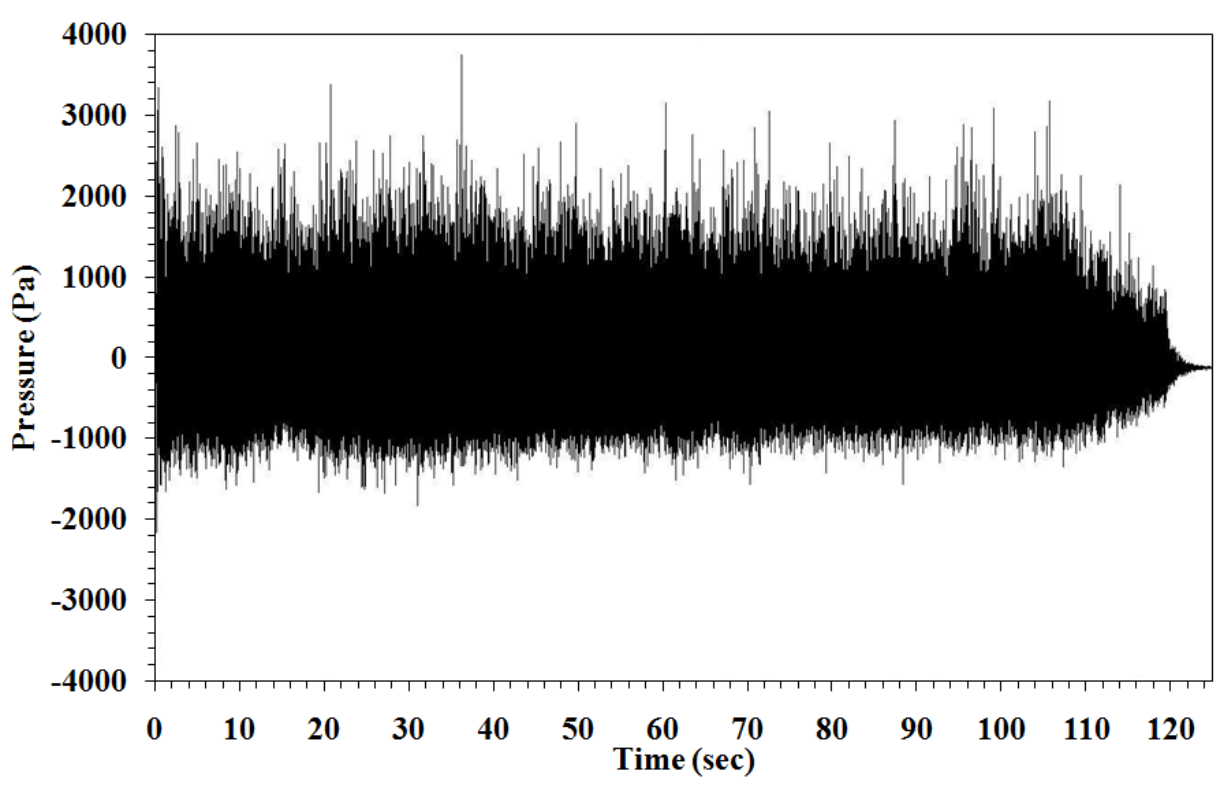

$67 \mathrm{~m}$ and 90-deg from nozzle exit plane (17 nozzle diameters)

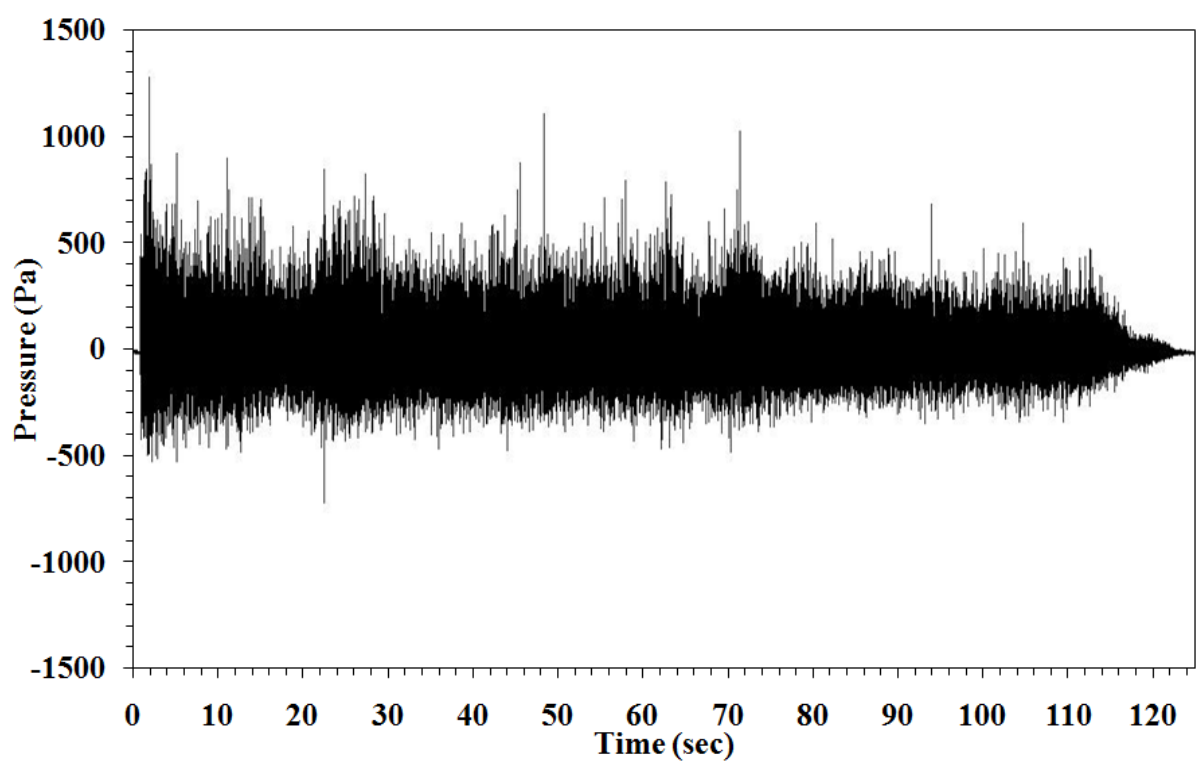

$304 \mathrm{~m}$ and 90-deg from nozzle exit plane (79 nozzle diameters) 


\section{Nozzle Vectoring and Thrust Effects}



\section{1/3 Octave Band Spectra}

$304 \mathrm{~m}$ at 46-deg off motor centerline

\section{TEM-13}

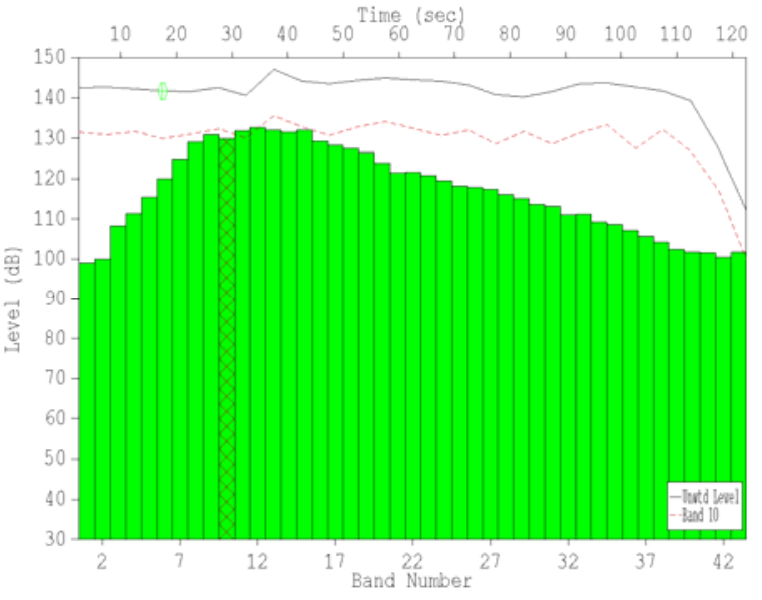

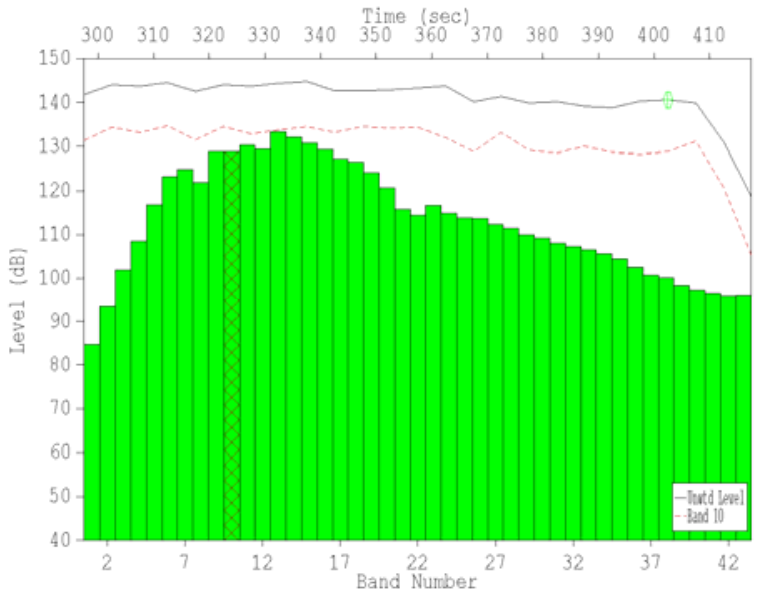

$304 \mathrm{~m}$ at 56-deg off motor centerline

FVM-2

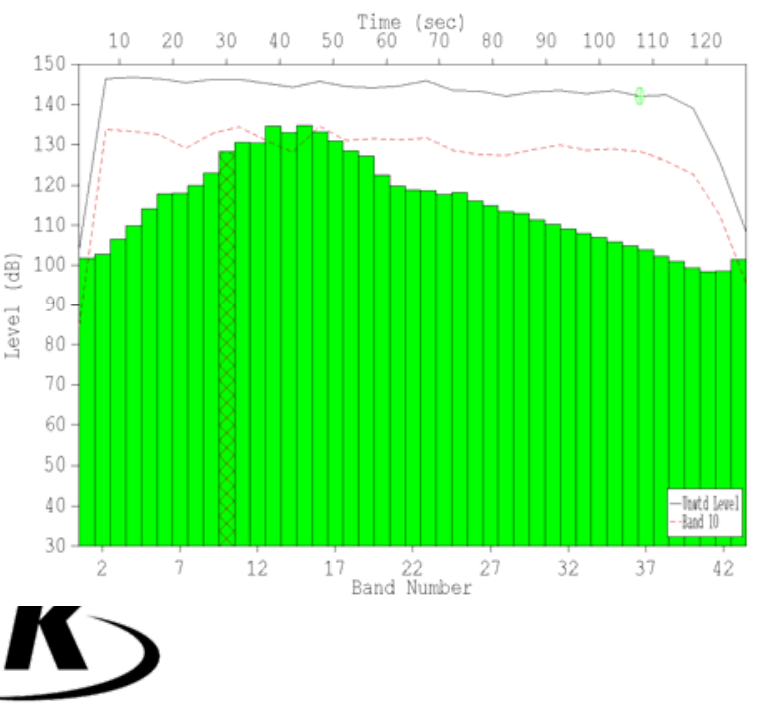

FSM-15
FSM-15

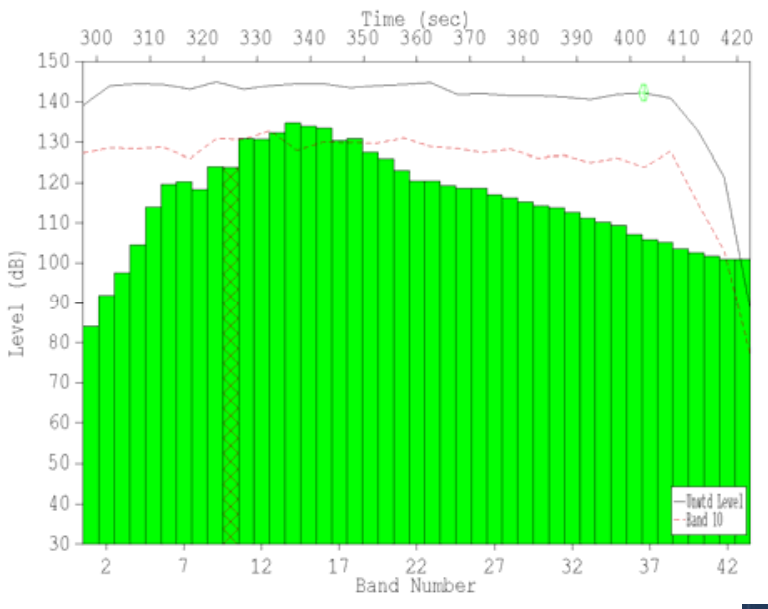

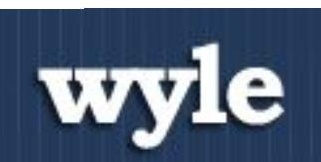




\section{Wind Effects on Measured Spectra}

- TEM-13 and FSM-15 had little to no wind

- FVM-2 had higher wind speeds during test

- Wind effects 'forced' ground effect, causing destructive interference to the data at approximately $100 \mathrm{~Hz}$

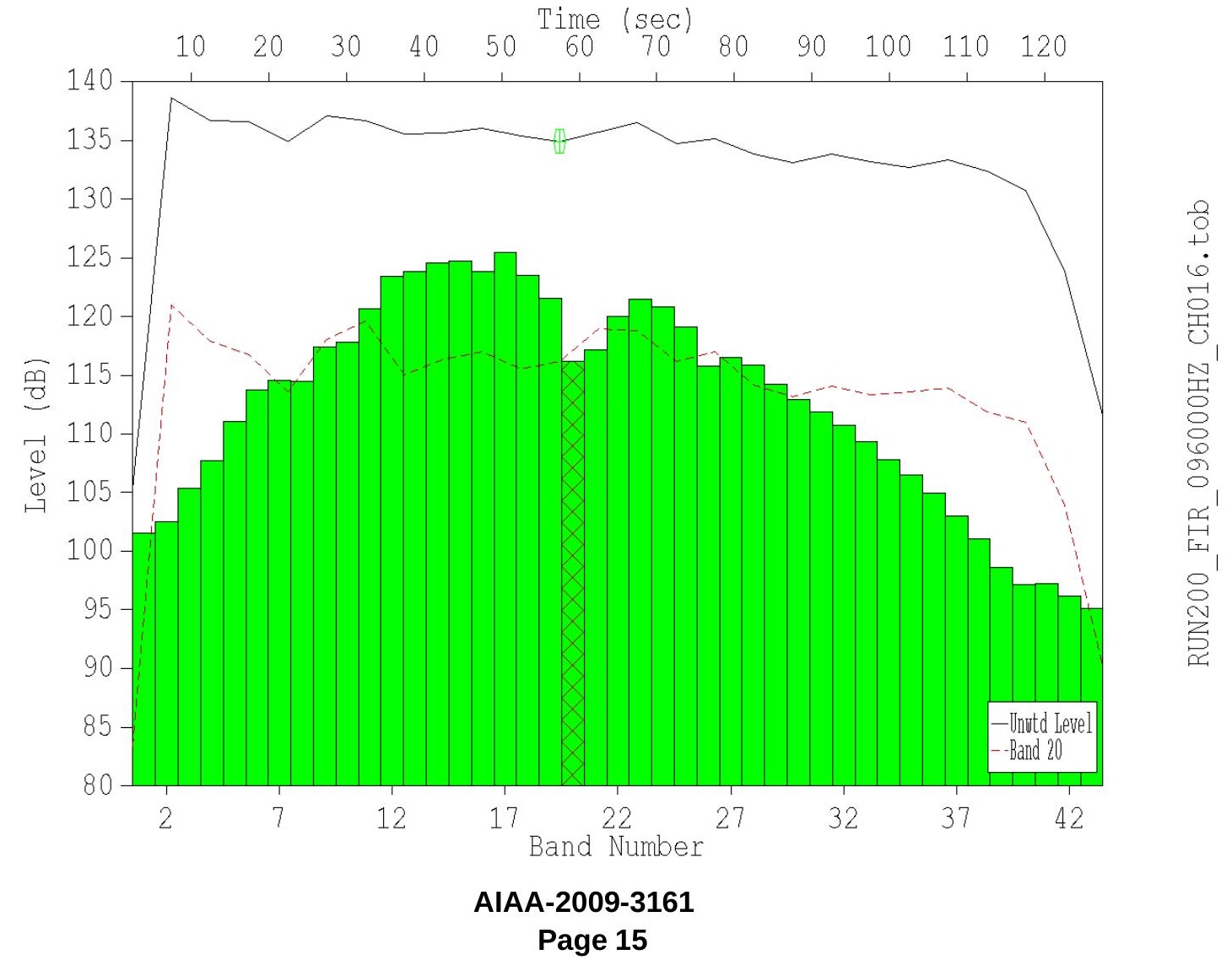




\section{Near-field Sound Pressure Levels}

- FSM-15 had seven spatial measurements axially oriented parallel to thrust centerline

- Levels show peak sound pressure levels 23 nozzle diameters downstream of nozzle exit plane

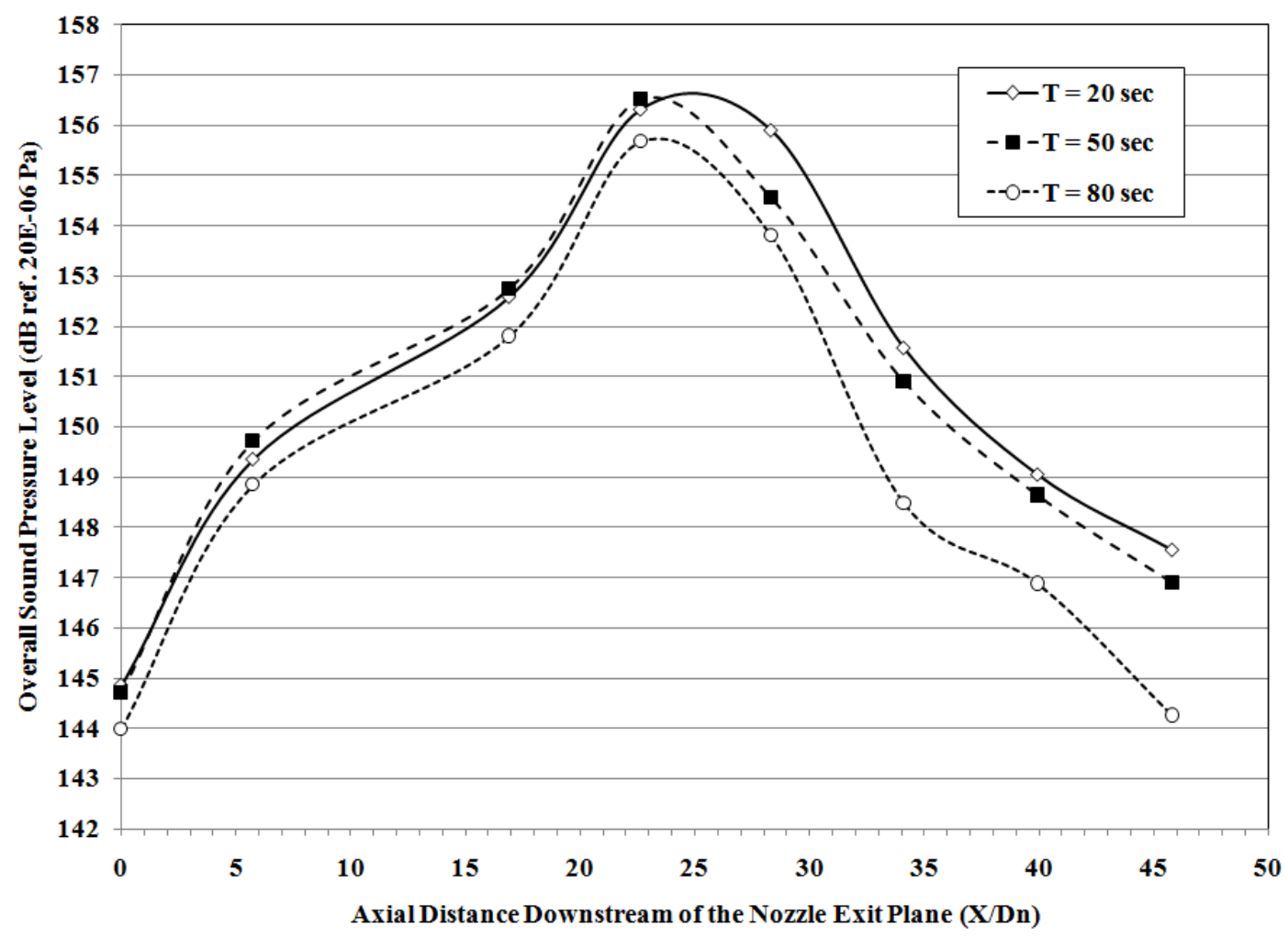




\section{Far-field Sound Pressure Levels}

- FVM-2 and FSM-15 had circular array at $304 \mathrm{~m}$ away from nozzle exit plane (79 nozzle diameters)

- Peak lobe occurs at approximately 50-deg at evaluation time of $50 \mathrm{sec}$

- Other times show similar result

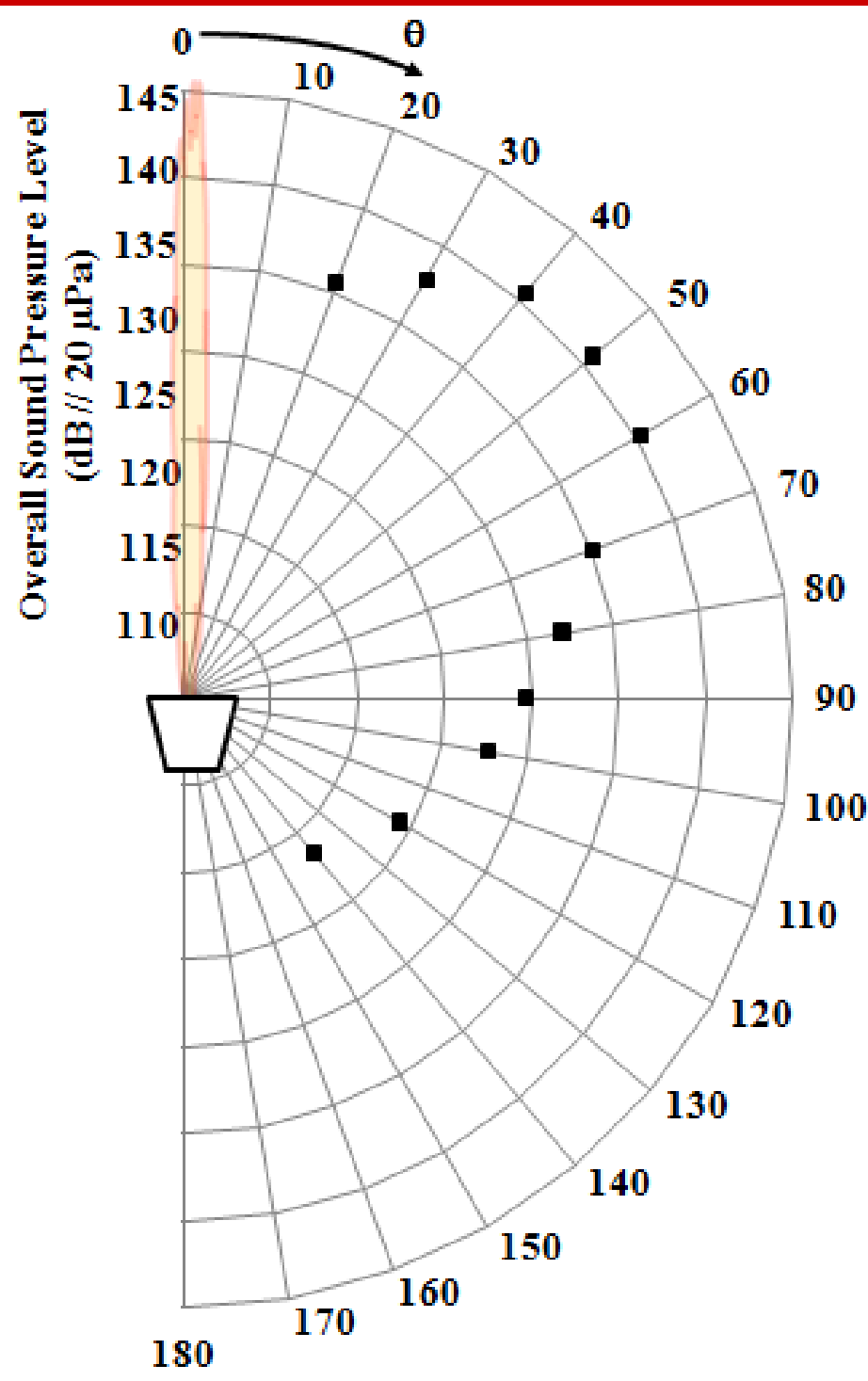




\section{Conclusions / Future Work}

- Teamwork led to unique acoustic data collection

- Collected results are still being analyzed for further understanding

- Data will be used to update model prediction methods

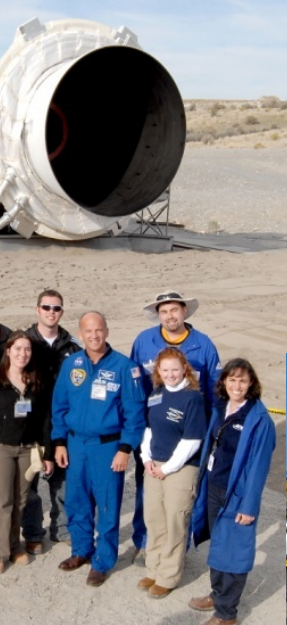

QUESTIONS?

政
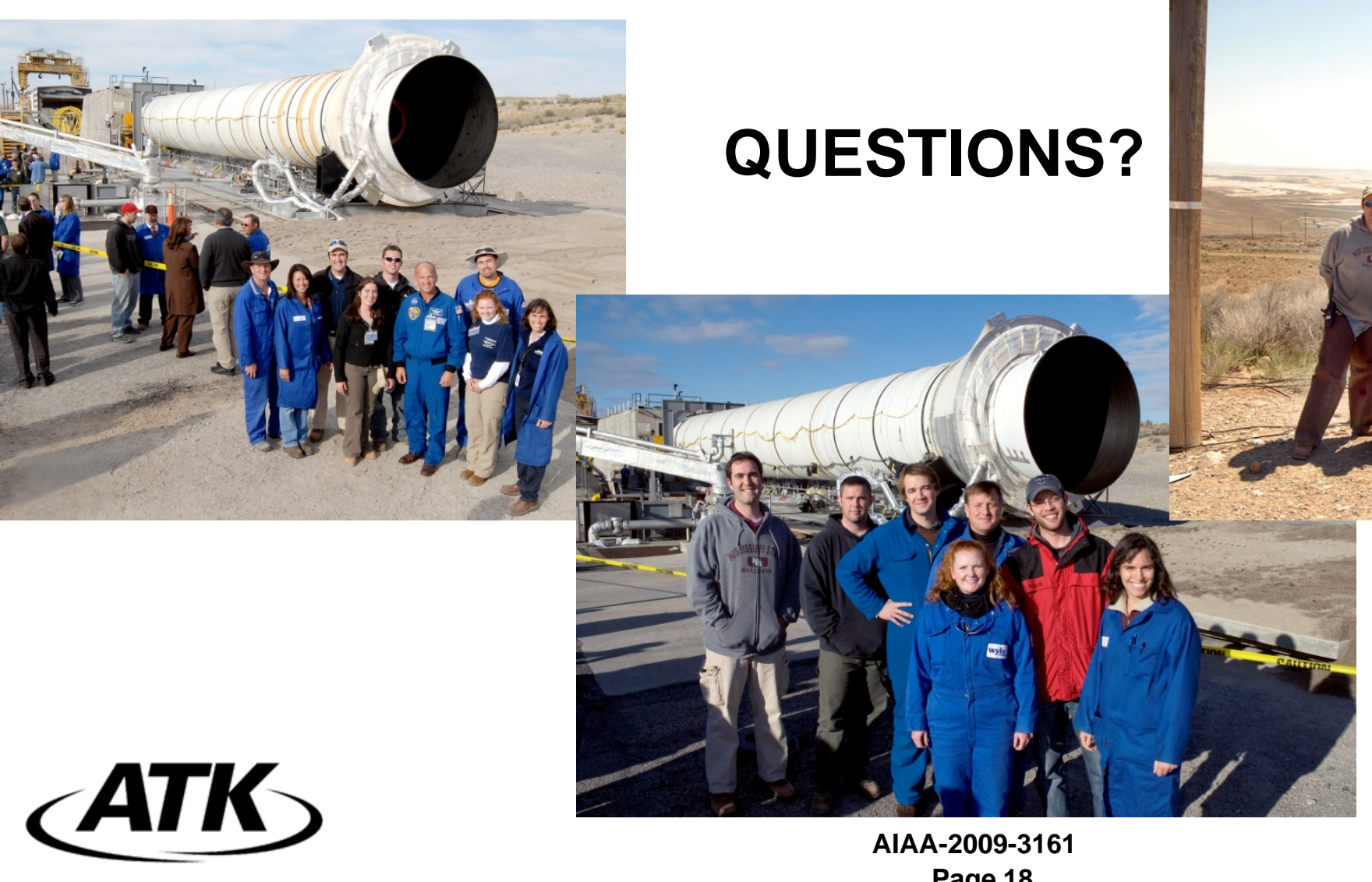

AIAA-2009-3161 